\title{
Reassessing Thermal Comfort in Modern Architecture: E.1027 as a Case Study
}

Galiano-Garrigós, A. ${ }^{1}$; Marcos, C. L. ${ }^{2}$; Kouider, T. ${ }^{3}$, Juan Gutiérrez, P.J. ${ }^{4}$

1 University of Alicante, Spain. Department of Architectural Constructions, University of Alicante Polytechnic School - EPSAlicante, Carretera San Vicente del Raspeig s/n, 03690, San Vicente del Raspeig (Alicante), Spain. antonio.galiano@ua.es (corresponding author) https://orcid.org/0000-0003-0603-4511

2 University of Alicante, Spain. Department of Graphic Expression, Composition and Projects, University of Alicante Polytechnic School - EPSAlicante, Carretera San Vicente del Raspeig s/n, 03690, San Vicente del Raspeig (Alicante), Spain. carlos.marcos@ua.es https://orcid.org/0000-0001-5272-0841

${ }^{3}$ Robert Gordon University Aberdeen, UK. Scott Sutherland School of Architecture \& Built Environment, Garthdee House, Garthdee Road, Aberdeen, AB10 7QB, Scotland, UK

T.kouider@rgu.ac.uk https://orcid.org/0000-0002-7856-7408

${ }^{4}$ University of Alicante, Spain. Department of Graphic Expression, Composition and Projects, University of Alicante Polytechnic School - EPSAlicante, Carretera San Vicente del Raspeig s/n, 03690, San Vicente del Raspeig (Alicante), Spain.

pablo.juan@ua.es

https://orcid.org/0000-0002-0507-7811 


\begin{abstract}
There is a general agreement that much of the syntax of modern architecture contributed to design buildings that were often inadequately adapted to climate conditions and, consequently, produced uncomfortable buildings. This would eventually spur critical regionalism and criticism over modern architecture. However, there are some renowned examples that, while consistent with modern tenets, prove that assumption to be wrong. Amongst them the E.1027 house designed by Eileen Gray and Jean Badovici stands out. The building is a genuine example of a modern architectural site-specific design considering its effective adaptation to local climate conditions.

This research aims to contextualise, quantify predicted thermal performance, and assess the quality of the E.1027 overall design in relation to thermal comfort. Most significantly, the house's adaptive design to achieve indoor thermal comfort values throughout the year. Thus, the original texts of Gray and Badovici on the E.1027 are contrasted with the results obtained from a series of simulations using thermal performance specialist software. A data rich 3D construction model was built which allowed the export of geometrical data to other simulation and analysis tools. The model was also used to evaluate sun exposure, to analyse the influence of shading devices. Two environmental evaluation software programs were used to analyse the impact of the different types and sizes of windows and solar control devices, and how these affected interior illumination levels. A combination of three methods was used to assess the building's expected thermal comfort performance, using the hourly data obtained from the software analysis process. Firstly, Givoni's Bioclimatic Chart was used to define a comfort zone for the building; secondly, Fanger's statistical analysis method, used to define a thermal comfort zone through the predicted mean vote. Thirdly, the Adaptive Model defined by the ASHRAE 55 allowed the evaluation of the thermal conditions in occupant-controlled naturally conditioned spaces.

These simulations and environmental analysis results demonstrated that Gray's and Badovici's deep understanding of the sun's impact and the cross ventilation needed to provide comfort can be modelled and confirmed. All passive design architectural elements evaluated in this research proved to have played a key role in the process of providing predicted thermal comfort values, just as it was foreseen by Gray's and Badovici's design, and anticipated in their writings.

This comparison demonstrated that the designers did indeed produce a design as sophisticated as it was comfortable, while distilling the two major architectural trends at the onset of modernity: neoplasticism and Corbusian imprint. Moreover, as a corollary, the paper argues that modernity in architecture did not necessarily contradict the idea of comfortable architecture and adaptation to local climate conditions when embracing modern aesthetic principles.
\end{abstract}

\title{
Keywords
}

Thermal comfort, climate, simulation tools, modern architecture, E.1027, Eileen Gray 


\section{Introduction}

Villa E.1027 (Fig. 1), designed and built between 1926 and 1929 in Roquebrune-Cap-Martin (France) by Designers Eileen Gray and Jean Badovici has, in the last few decades, been the subject of critical architectural debate. Most of this criticism has been a consequence of the polemical actions and stances perpetrated by Le Corbusier (Constant, 1994; Colomina 1993; Rault, 2005; Adam, 1989; Benton, 2017; Adam 2000; Espegel, 2010; Marcos 2011) which, in turn, have spurred a series of passionate positionings within academia. Yet, little heed has been paid to date to the house's value in terms of thermal comfort design.

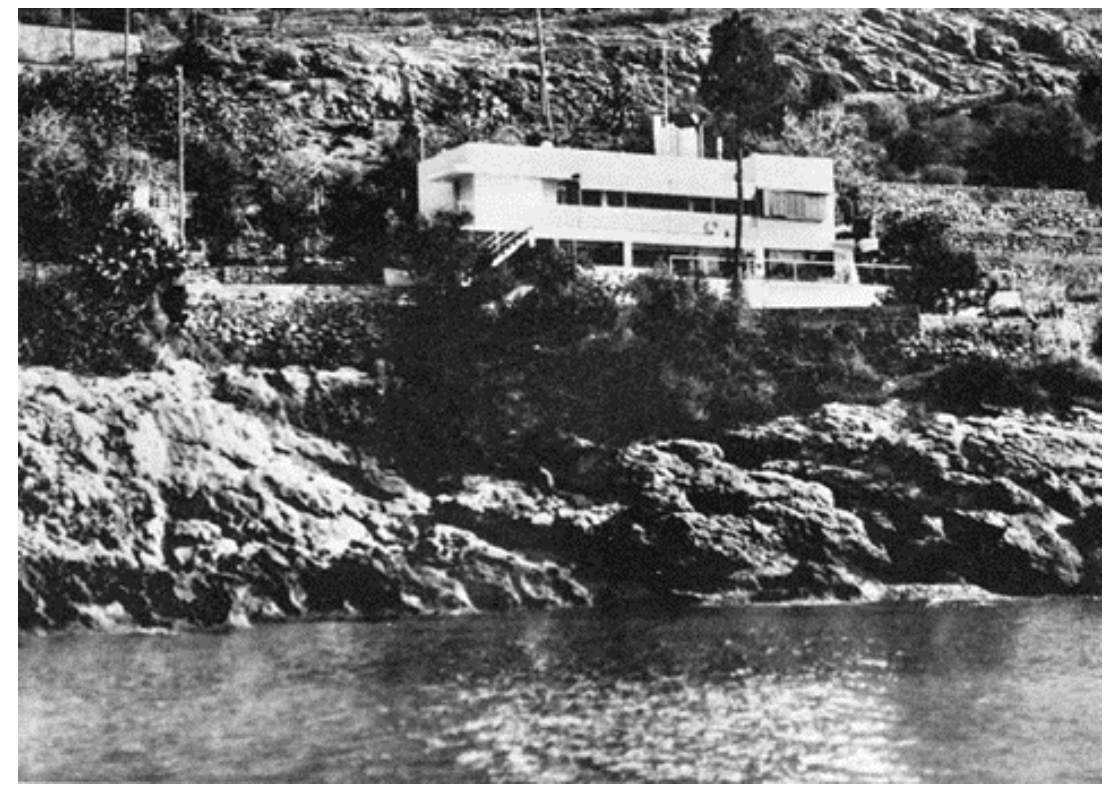

Figure 1. Eileen Gray and Jean Badovici, Villa E.1027 as seen from the sea, Roquebrune-Cap-Martin, 1929.

A sustainable design maximises comfort while minimising environmental impact, taking advantage of smart design solutions that increase its efficiency in accordance with climate conditions. This villa includes a series of these design solutions that demonstrate a deep knowledge of addressing climate issues and comfort. Bodily comfort is related to wellness, a sensation that has much to do with hygrothermal comfort: the balance between our heat interchange with the immediate environment and our body heat production. Gray and Badovici referred to this idea of well-being as the joie de vivre, a certain critical reading of modern hygiene principles (Ryan 2010, p.340). In their description of the house published in the influential architectural journal L'Architecture Vivant -of which Badovici was editor-read: "External architecture seems to have absorbed avant-garde architects at the expense of the interior. As if a house should be conceived for the pleasure of the eye more than for the wellbeing of its inhabitants" (Gray, Badovici, 1929b, p. 23). The design of the E.1027 is evidently site-specific, a conscious approach to local climate conditions, and this genuine notion of dwelling in connection to well-being.

The main aim of this research is to show that, despite a general assumption to the contrary, there were examples of modern architecture that whilst being fully compliant with the design trends of the time, they were also well adapted to location and climatic conditions. Thus, using the E.1027 house as a case study, this research assesses and analyses the passive design solutions implemented. It also quantifies, through the use of simulation software, to what extent these design solutions were efficient and adequate to provide indoor thermal comfort to the inhabitants throughout the year. The house was critically assessed in relation to the intellectual positioning of its designers. The latter, as it shall be demonstrated, were perfectly familiar with the local climate, and conceived a series of original passive design solutions that contributed to achieving above-average results in terms of thermal comfort. At the same time, it is also the aim of this research to demonstrate that new technologies and simulation tools can be very useful to increase our knowledge and understanding of how this singular architectural piece performs. 


\section{Background}

At the onset of modernity, a major concern on the constructive systems, on the one hand, and the architectural language that could be derived from it, on the other, inspired the main trends and architectural theories alike. Modern architects were persuaded by the importance of rationalising design, and were involved in the exploration of a new approach to architecture that should revolutionise conception and the referents of discipline, based for centuries on classicism (Summerson 1966). Gray's and Badovici's design for the E.1027 was certainly influenced by the two main trends that had already begun to prefigure the evolution of modern architecture: neoplasticist architecture and Le Corbusier's very influential work and theories epitomised in his 1920s villas (Hitchcock, Johnson 1932). However, the E.1027 is more sophisticated and site-specific, trying to avoid a purely formal abstract approach solely centred on the object itself, but rather making the house pivot around the dweller, the idea of comfort, and the site. In fact, "Gray applied the Stijl concept of the total work of art to her more concrete and material notions of dwelling" (Constant 2000, p.79). As her biographer informs, she clearly stated that "A house is not a machine to live in" (Adam 1989, p.319). The rich space density and the carefully crafted interiors of the E.1027 can be interpreted as an implicit critique towards Corbusean rationalistic and neoplasticist abstract principles, even if it integrates many of these tenets.

In one of the few texts signed by Gray and Badovici, De L'Eclecticisme au Doute, written in the form of a dialogue, what seems to be Gray's voice argues against hygienist ideals: "Hygiene to bore you to death! Hygiene that is badly understood because hygiene excludes neither comfort nor activity. No, the Avantgarde is intoxicated by mechanization" (Gray, Badovici, 1929a, p. 20). It is important to highlight her focus on human needs rather than on fashionable or abstract aesthetic principles. Originally a rug, furniture and interior designer by trade, the idea of comfort naturally sprung in her scarce but extraordinary architectural designs (Rykwert, 1971, p.67).

These writings could be aligned with other architects that intended to improve people's quality of life in buildings. Le Corbusier paid special attention to sunlight control and the possibilities of the free façade once the enclosure had been liberated from the load-bearing constraints, and its comparative lightness reduced its traditional thermal buffer effect. He experimented with large double height glazing in some of his early 1920s projects (Atelier Ozenfant, 1922; Villa Roche-Jeanneret, 1923) oriented to the north, but radically changed this pursue when he first attempted a generous glazing to the South in his 1927 house for the Wesissenhofdlung in Sttutgart (Requena-Ruiz, 2011, p.53). Rayner Banham alluded to this apparent contradiction and a certain loss of "common sense", although he noted that the main views to Stuttgart were facing in that direction (Banham 1969 , p.165). Wright's organic architectural approach, with generous overhangs to protect the glazing from exposure to the sun in his prairie houses, contrasted with Le Corbusier's syntax while partially serving as an architectural imprint over neoplasticist architecture.

Le Corbusier's approach was more technological and somewhat more confident on the technical possibilities of industrialisation and a machinist conception of architecture. He tried to develop a technological solution to achieve air conditioning through his mur neutralisant and his respiration exacte on which he proposed: "a single house for every country, every climate, a house with respiration exacte [...] Truly versatile buildings capable of equally performing in the tropics or in the glacier regions" (Torres-Cueco 2004, p.133). He tried to implement this mur neutralisant and the respiration exacte on large scale buildings such as the Centrosoyuz in Moscow (1928-1936), the Cité de Refuge (1929-1933) or the Swiss Pavilion (1930), both in Paris. However, the little advance of these technologies at the time, and their considerable costs, together with the lack of proper funding to implement them, would end up in one of Le Corbusier's and Pierre Jeanneret's greatest built failures in their Cité de Refuge. The south façade was an interrupted glazed plane that, although originally planned with the respiration exacte, its disproportionate costs -up to a 50\% repercussion in the original budget (Requena-Ruiz 2011, p.55)- made it unfeasible. As a result, "the absence of any cooling system in summer, and the impossibility of opening the fixed windows on the south façade would doom these measures to failure." (Cohen, 2004, p. 51). The interiors were so uncomfortable that the architects, after a long trial, ended up being required to install 45 operable windows on this façade at their personal cost but, luckily for them, Le Corbusier managed to rebuild a brise-soleil façade in 1951 that would effectively shade the now recessed glazing, after the Second World War bombardments produced the collapse of the entire façade (Requena-Ruiz, 2011, p.53). This, in fact, was part of the more conscious approach to solar protection derived from his collaboration with Niemeyer, Costa, Reidy, in 1936 for the Ministry of Health and Education and his project for the Skyscraper in the Marine district in Algiers 
of 1938.

Nowadays, aided by simulation technologies, the awareness and efficiency of some of these designs is confirmed, showing they would not have been very different despite the limited analytical tools available (Requena-Ruiz, 2016). This proves their value, not only because of their historical assets, but regarding their predicted comfort. These designs accompanied, in some cases, by writings, diagrams and studies confirm their author's intentions and their conscious approach to some of these issues.

This is the case of Eileen Gray and Jean Badovici, whose writings on the E.1027 display a critique of a simple and straightforward application of hygienist principles suggesting an environmental climatic awareness, and a more nuanced approach. Its fine passive design features, adaptation to the local environment, and their idea of comfort, have rarely been considered in architectural research -with few exceptions (Constant, C. 1994) - or only partially analysed from a climatic efficiency point of view (Ryan, 2010).

Some of these strategies could find their origin in vernacular architecture which has traditionally addressed certain design values to benefit from local climatic conditions in the pursuit of comfort. In the case of buildings adapted to warm or mild-warm weather, the size of the openings, the use of shading systems to achieve solar protection, and cross-ventilation, have been revealed as the most effective passive design solutions combined with light enclosures. Compliance with these principles may serve as a guide for an efficient and comfortable building design that may not involve great technological enhancement (Meir and Roaf, 2003).

\section{Assessing thermal comfort in architecture}

Many methods have been developed to analyse and predict the wellbeing of building occupants. Thermal comfort could be defined as the bodily condition that expresses thermal satisfaction and wellbeing within the built environment, and is assessed by subjective evaluation. Developing these methods was one of the key concerns of building and environmental engineers for decades; such interest intensified with the decline of modernism. Bioclimatic architectural design and evaluation methods such as Givoni's (Givoni, 1969), Fanger's (Fanger, 1967) and Olgyay's (Olgyay et al., 1963) have been widely used in this regard. These methods are based on static approaches to the evaluation of thermal comfort based on building geometry (Givoni's), users' opinion (Fanger's), or temperature and humidity (Olgyay's). More recently, ASHRAE specifications, partially based on these methods, have implied and updated methodology.

Of these methods, Fanger's, based as it is on statistical individual thermal perception, is closer to what was written by Gray and Badovici on comfort and climate in architecture. This method has been thoroughly assessed by some authors; accordingly, it can be stated that the PMV - predicted mean values- can provide consistent threshold values for different living situations and climates (D'Ambrosio Alfano, Palella and Riccio, 2013). However, it has also been sustained that those methods based on the static PMV model work better in air-conditioned buildings than in naturally ventilated spaces without the users' interaction (Yang, Yan and Lam, 2014). In the case of locations with a high humidity, users were keen to accept higher air speed than those recommended by comfort standards (Kumar et al., 2019). In this sense, comfort can be improved by designing interiors with adequate materials (Fabbri, 2015).

Recent findings in the study of thermal comfort are based on the development of adaptive thermal comfort that considers the variations that occupants can effect, even under the conditions of neutral predicted mean values, to feel within a range of comfortable values. This has been widely researched by different authors trying to establish the adequate limits (Hellwig et al, 2019) (Olesen and Parsons, 2002) (Brager and De Dear, 1998) (Schweiker et al., 2012) (Humphreys and Hancock, 2007) (Halawa and Van Hoof, 2012) and they are, in fact, part of different regulations developed by ISO and ASHRAE. The consideration of dynamic modification of the building environmental conditions, internal and external, as well as the individually triggered (Fabbri, 2015) could be closer to the interaction of the user with architecture and its attendant services and devices, as conceived by Gray and Badovici.

There are several strategies that people can use to adapt architecture to climate and environment. People use these adaptive mechanisms and the opportunities they offer to provide comfortable conditions. The effect of these adjustments can explain the different responses that people perform in buildings to operate 
these controlling systems to reach comfort situations. In terms of thermal comfort, the range of conditions which will be found acceptable at any given time fall within the interval of + or $-2^{\circ} \mathrm{C}$. Giving occupants the necessary control to make themselves comfortable may increase this range, while the feeling of discomfort increases when occupants lose it (Nicol and Humphreys, 2002).

Analysis of the performance of modern architecture buildings has been carried out by other researchers to assess the implemented design solutions, introducing post occupancy evaluations to highlight the effective building performance more than simply its iconic architectural values (Nicol and Roaf, 2005). In this process, contemporary quantitative simulations and modelling tools have been used to unveil bioclimatic design features in this type of buildings, that can be used as examples for future architects and engineers (Granadeiro et al., 2013) (Escandón, Sendra and Suárez, 2015).

Some studies have analysed the impact of restoration of these iconic buildings. These interventions show that they should re-establish the original design as some of these restorations have shown levels of thermal comfort similar to what could be expected nowadays with the use of modern conditioning systems. These findings corroborate the need of reaching a proper relation between passive and active solutions in new buildings as well as in restorations (Geva, 2008). However, it has also been shown that architecture lovers can indulge some uncomfortable situations for the sake of good design as even the 'pleasure for the eye' that Gray and Badovici denounced, may still be appealing to connoisseurs. Efficiency and comfort should be considered complementary rather than alternative (Roulet et al., 2006).

Moreover, developing design solutions that contribute to achieve comfort situations in buildings have been thoroughly investigated by different researchers. Facing guidelines that aim to facilitate the adoption of adaptive comfort principles to obtain better buildings have been proposed by different authors (Shi et al., 2016) (Bluyssen, 2010). Something that designers and the people responsible for architectural tuition should be well aware of.

\section{Solar protection, natural lighting, ventilation, usability and comfort}

In order to achieve comfortable values in a mild-warm weather, it is absolutely fundamental to control and protect from solar radiation during the warm season. One of the most effective devices that help to control the sun are window shades. Some researchers have nonetheless shown that not all the shades are suitable for every location. Blind type and geometry have to be adapted to each location (Zhang and Birru, 2012).

Additionally, the sun impacts in a different way depending on the latitude of a given location, on which the solar radiation as the key factor depends most. The seasonal effect is also very significant when considering building orientation. The variation of the occlusion is notably affected depending on the time that the rooms are exposed to sunlight. In this sense, occupants' preferences play a very important role, as sunlight perception changes among individuals. Amongst these preferences, maintaining a visual link with the exterior is one of the most demanded (Zhang and Barrett, 2012).

Natural light in buildings is designed according to minimum illuminance requirements to achieve acceptable visual conditions especially related to the kind of activities to be developed inside. Nevertheless, some studies confirm that a proper illuminance improves human activities (Darula, Christoffersen and Malikova, 2015). Generally speaking, people enjoy having direct sunlight inside buildings, provided thermal and visual discomfort are avoided. Obviously, the appreciation of the sun is dependent on climate, and sometimes, on tradition. It is a common practice in building design to deal with the thermal aspects of sunshine and its control, while, frequently, visual aspects of natural lighting are not adequately considered (Ne'Eman, 1974).

Shading should be considered as an integral part of the fenestration system design in mild-warm weather in order to balance daylighting requirements with the need to reduce solar gains during the warm season. Some studies have demonstrated that adaptive shading systems improve a building's performance both from energy use and comfort point of view (Tzempelikos and Athienitis, 2007). 
The other key factor in this type of climate is the control of ventilation to cool the house during the warm season, especially if exposed to sea breezes. Much research has been published on this issue finding that single-side ventilation and cross-ventilation can have a good effect on cooling and improving air quality in buildings with different functions, as long as the height and depth of rooms is properly designed (Cuce et al., 2019). Additionally, the interrelation between ventilation and other factors such as indoor and, outdoor conditions, building characteristics, as well as occupants' behaviour, have also been studied. Thus, it can also be stated that adaptive ventilation systems tend to improve energy efficiency and, simultaneously, lead to more comfortable interiors (Chenari, Dias Carrilho and Gameiro Da Silva, 2016).

Finally, the idea of comfort and design must also consider other variables different to that of the hygrothermal sensation. Features such as the ergonomic conception and the functionality in the design of the equipment, furniture and furnishings in accordance with the conception of the Gesamtkuntswerk (total work of art) ideals also contribute to improve it. Gray wrote to this regard "the object should be given a form that is most suited to the spontaneous gesture or instinctive reflex that corresponds to its purpose" (Gray, Badovici 1929b, p.18). This was also inspired by the integral conception of architecture and decoration pursued by neoplasticist architects which she deemed so necessary as to radically state "architecture must be its own decoration" (Gray, Badovici 1929b, p.19). The smallest details in the house were conceived to maximise comfort, including architectural details, the interior design, as well as the furniture, the fittings and the furnishings for which Gray designed almost 300 different elements (McGuckian 2016).

\section{Research Method}

One of the objectives of this research is to show that Gray and Badovici had a climatic conscious design approach based on a deep understanding of the sun charts and the principles needed to design a comfortable summer house in relation to site and climate. To this end, the house has been contextualised and compared with other architects' concerns on climate and comfort based on the published evidence, paying special attention to the texts written at the time. Accordingly, the writings by Gray and Badovici on the E. 1027 have been critically approached and confronted with the results obtained from the modelling of the house using contemporary environmental assessment simulation software. E.1027 is a museum, and therefore the views of the occupants cannot be captured, as would be common in thermal comfort writings, and for the same reason it was not possible to consider post-occupancy evaluations and measurements of the building.

The first part of the research is dedicated to the analysis of the house's performance in terms of sun exposure and ventilation. This is confronted with the design solutions that Gray and Badovici carefully conceived to ensure comfort, taking advantage of the orientation, the cool sea breezes, natural lighting and solar protection when needed. The impact of each of the features designed to control the sun is evaluated both in summer and in winter. Shadows and illumination are compared and related to what Gray and Badovici wrote with regard to the E.1027. Their successful design shows that modern architecture tenets were not discordant with a comfortable design for a cheerful living.

The second part of the research is centred on demonstrating through simulation software, that the location and the adopted design solutions provide predicted thermal comfort values in the house during the period of the year it was intended for. Accordingly, the impact of the definitory elements of the house is assessed analysing the overall building's performance to this regard. This evaluation has been carried out by using simulation software used nowadays to simulate buildings' performance, comprising three different methods that evaluate thermal comfort in buildings.

The yielded results are used to evaluate the predicted thermal comfort values as a first step using Givoni's methodology and bioclimatic charts (Givoni, 1969). These are confronted with the building's design features that have an impact on its interior comfort conditions. In a second step, the statistical method defined by Fanger (Fanger, 1967) is used. This method uses a scale of values directly related to the percentage of people that would feel comfortable in an interior space under certain conditions, thus providing a quantifiable way to predict comfort sensation statistically based. Finally, the Adaptive Method defined by the ASHRAE 55 (ASHRAE, 2020) has been used to complete the simulation process. This method allows to consider reaching thermal 
comfort scenarios through the active operation of the building's passive design solutions by the occupants. The results have been confronted with Gray's and Badovici's design intentions and the interaction between dweller and architecture.

\section{Software and methods used}

The simulation of the E.1027 performance first step entailed the construction of a detailed 3D model using Autodesk Revit 2020. This BIM modelling tool allows exporting the geometrical data to other simulation and analysis tools. The evaluation of the sun exposure to analyse the influence of the shading devices is developed with this software.

The analysis of the influence of the different types of windows and the sun control devices from the illumination point of view is performed using both Sefaira v.2020 and DesignBuilder v.7. Sefaira is a software developed by Trimble that allows the evaluation of the building's performance under different parameters using a Revit 3D model. It allows us to run a detailed analysis evaluating illumination, energy performance and comfort. The influence of the different shading systems over comfort is performed using DesignBuilder. This tool is widely used and may be considered a complete software simulation tool for the evaluation of buildings' performance. It uses EnergyPlus as its calculation engine, and it allows the introduction of the complete building construction model, including materials' thermal performance data. It may perform hourly, daily and monthly analysis, yielding a wide range of information such as energy consumption, temperature ranges, relative humidity levels and different types of comfort analysis.

The hourly data analysis obtained from DesignBuilder is used to assess the building's design expected thermal comfort under three different methodologies. The Bioclimatic Chart designed by Baruch Givoni allows to define a strategy to obtain a comfortable building according to the building's hygrothermal conditions for a specific date and location (Givoni, 1992). It is built over a psychrometric chart that defines two main zones: the comfort zone delimited by the concurrent combined values of temperature and humidity and extended comfort zones delimited by other design factors related to the building.

The thermal comfort analysis performed with Givoni's method is done through the Psychrometric Chart App Tool. It is a web-based app developed by Andrew Marsh that displays a psychrometric chart over which a range of thermal comfort metrics can be overlaid (Marsh, A. J. 2018). Energy Plus weather data files (.epw) and results (.CSV) provided by simulation programs can be loaded to the app. The app is user-friendly and permits annual/hourly climatic data to be graphed in a psychrometric chart offering the possibility of analysing building thermal performance on a daily basis.

The second method of analysis is developed using the methodology proposed by P. O. Fanger. This method is based on a statistical analysis of the largest possible percentage within a given group of people that experience thermal comfort in an interior space under a given set of conditions that include a hygrothermal situation, a given activity, and the clothing worn (Fanger 1967, Diego-Mas 2015). It calculates two indexes called Predicted Mean Vote (PMV) and Predicted Dissatisfied Percentage (PPV) that show the mean thermal sensation of an interior environment and the percentage of people that will feel comfortable or uncomfortable under those parameters. Values of the percentage of unsatisfied persons (PPD) of up to $10 \%$ will reflect a satisfactory situation for most people (90\% satisfied), while higher values will indicate a situation of thermal discomfort. This value for the PPD at $10 \%$ corresponds to the limits -0.5 and 0.5 indicated for the PMV.

The combination of Givoni's and Fanger's methods allow a more comprehensive analysis, and the validity of its results is more assured (van Hoof, 2008). The limits to Fanger's method are defined in the ISO 7730 (International Standard Organization, 2005), recommending it should only be used if the metabolic rate is between 0.8 and 4 met., and clothing insulation between 0 and 2 clo. The outdoor temperature must be between 10 and $30^{\circ} \mathrm{C}$, wind speed between $0 \mathrm{~m} / \mathrm{s}$ y $1 \mathrm{~m} / \mathrm{s}$, and water vapour pressure between 0 and $2700 \mathrm{~Pa}$. The limits to Fanger's method defined by the ASHRAE 55 that establishes thermal comfort within the value range of -0.5 and 0.5 , have been adopted for this research.

The third method used to evaluate thermal comfort in the E.1027 is the Adaptive Method defined by the ASHRAE Standard 55. This method conditions its scope to some criteria that match the characteristics of the E.1027 house. It is designed to be used in buildings without mechanical cooling where a low activity rate is 
expected. It is to be noted that it is more efficiently applied to the living room as for the bedrooms the method has some limitations. Additionally, occupants must be able to adapt themselves to the indoor and/or outdoor conditions and the building must be located in a mild-warm area.

The adaptive method compares the building interior operative temperature with the upper and lower $80 \%$ acceptability limits obtained from the prevailing mean dry-bulb outdoor temperature for the 24-hour day after the use of the following formulas:

Upper $80 \%$ acceptability limit $\left({ }^{\circ} \mathrm{C}\right)=0.31$ temp +21.3

Lower $80 \%$ acceptability limit $\left({ }^{\circ} \mathrm{C}\right)=0.31$ temp +14.3
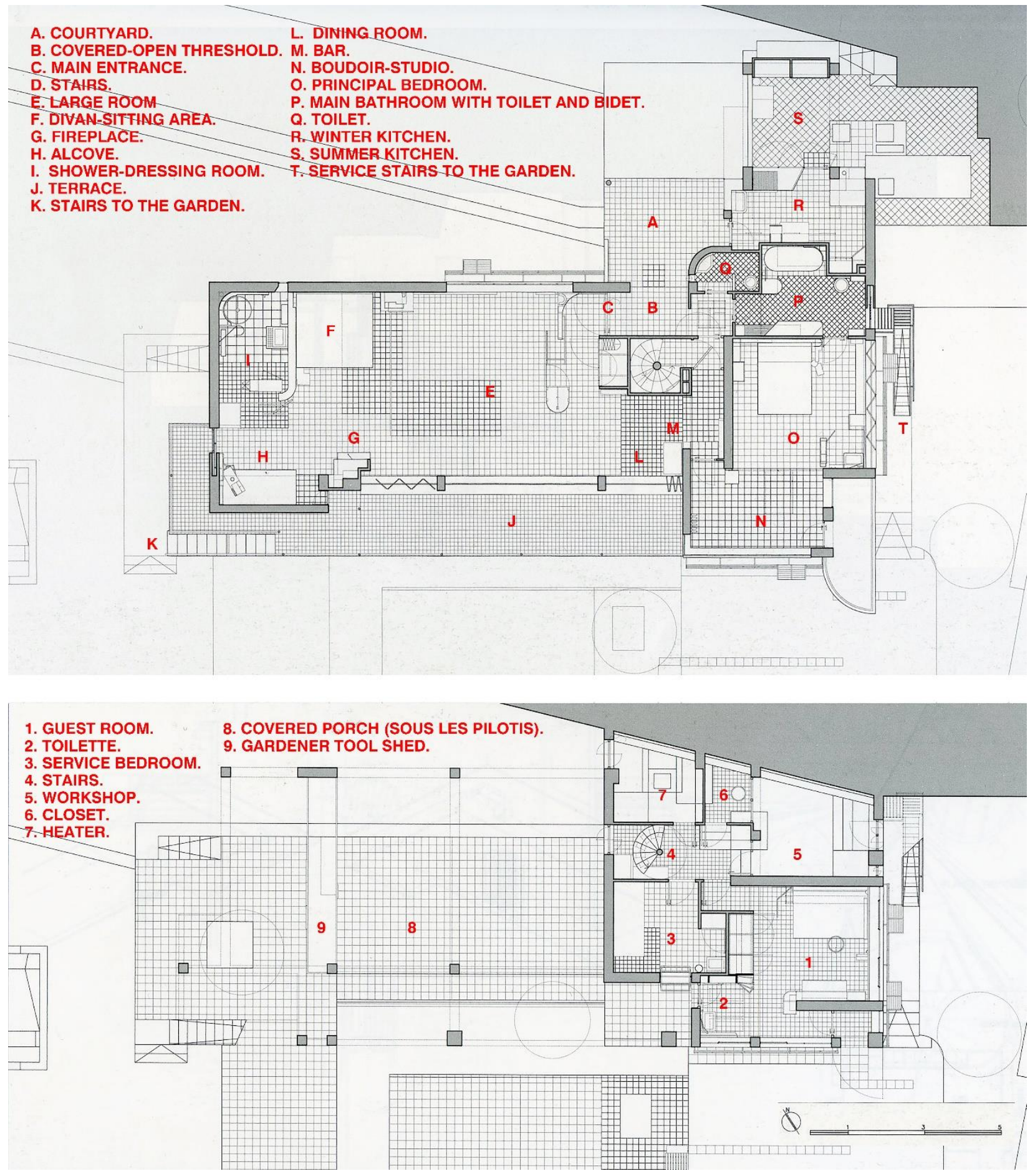

Figure 2. Eileen Gray and Jean Badovici, Villa E.1027. Upper and lower floor plans, 1929 (Espegel 2010). 


\section{The E.1027 Case Study: Architectural description and passive design solutions analysis}

The house was built as a summer house in a narrow strip of a rocky and steep terraced lemon grove limited by the sea and the railway on the upper limit, thus ensuring privacy (Adam 2000). The main prism of the house -corresponding with most of the program- is raised from the terrain level and supported by pilotis so that the main program comprises the multipurpose living room, the master bedroom, two bathrooms, the kitchen and the south terrace in a sort of piano nobile (Fig. 2). This generates the opportunity for a shadowed porch covered by the house itself, whose ventilation is guaranteed as the next terraced level of the terrain is recessed in section so that the sea breeze can freely flow through this space underneath the house to cool the main volume and this exterior porch "sous les pilotis" in the warm season. The lower level of the house interior comprises the guest bedroom, the service bedroom, as well as other utility areas. The house uses a reinforced concrete structure of columns and slabs (Espegel 2010, p. 57).

The ceramic brick board walls of the upper floor are $20 \mathrm{~cm}$. thick and those of the lower floor are $30 \mathrm{~cm}$. thick respectively (Espegel 2010, p.58); no insulation was used in housing as a standard at the time of its construction. It also features a somewhat sophisticated ventilated flat roof (Fig. 3) with a generous air chamber covered with hollow ceramic board, gravel, sand, callendrite and a concrete screed laid to fall over ceramic brick board lateral support layer supported by concrete inverted beams over the concrete slab. This data served to build the 3D model for this research that was used to analyse and quantify some basic results in relation to energy performance, despite the limitations of the available constructive data, as well as the simplifications that were accordingly necessary to assume.

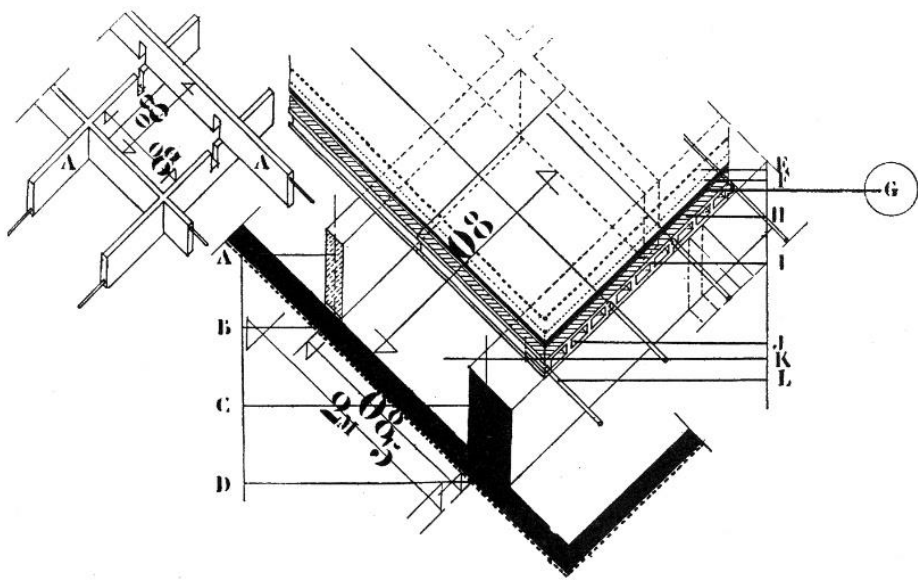

A. SUPPORTING RIBS LAID WITHOUT MORTAR

B. $300 \mathrm{KG}$. REINFORCED CONCRETE SLABS

C. INVERTED BEAMS (CROSS SECTION DEPTH UPWARDS)

D. CONCRETE FINISHED CEILING

E. GRAVEL

F. SAND

G. CALLENDRITE (WATERPROOFING MEMBRANE)

H. CONCRETE SLOPE

I. PERRIER HOLLOW ELEMENTS (CERAMIC BRICK BOARD)

J. SECOND AIR LAYER (WITHIN THE HOLLOW ELEMENTS)

K. FIRST VENTILATION LAYER $\mathrm{H}=0.4 \mathrm{M}$

L. STEEL REINFORCEMENT BARS

Figure 3. E. Gray and J. Badovici. Detail of ventilated roof (Gray, Badovici 1929b, p. 25).

It is noteworthy that this flat roof is not an inverted roof, where the insulation is provided above the waterproof membrane, in fact, it is a ventilated roof designed to protect overheating from summer sun exposure, probably inspired in traditional Mediterranean architecture. The ingenious constructive detail consisting of inverted beams produces a double skin roof with two different air layers reducing the temperature gain produced by sun radiation and leaving the greatest thermal inertia to the construction assembly below -the slab- to improve the thermal behaviour of the roof.

Gray and Badovici, designed special solutions to control the sun and to enhance cross-ventilation. Windows were designed and dimensioned to be flexible enough to control the amount of sun that would be let in or rejected, depending on the time of the year. Simultaneously, the use of elaborate partially orientable shutters allowed ventilation while keeping the sun under control. Their architectural design sought the users' complicity to achieve comfort by designing simple and effective low-cost solutions engaging them in the operation of these passive elements in accordance with the changing weather conditions.

Additionally, these passive design solutions to optimise sun control and ventilation -the two key factors impacting the house's predicted comfort performance- were carefully studied depending on the room orientation allowing the users to move inside the house and to perform different activities in the multi- purpose main living space or the master-bedroom, the two main spaces of the house on the first floor (Gray and Badovici, 1929b). 
Solar control devices were completed with a flexible shading sailcloth canopy and awnings that run along the south terrace. Cross-ventilation was carefully studied by locating opposite windows that could be opened or closed in different combinations, depending on wind strength, to achieve comfort conditions in every circumstance.

Badovici's and Gray's attitude was consistent with the modern conception of a need for a new architecture that would rationalise the discipline, disregarding old formulas based on tradition and primitive constructive systems, however introducing the notion of comfort as a new approach in the process of designing better buildings.

Although it is true that the so-called international style pretended a ubiquity that was proven mistaken by critical regionalism decades later (Lefaivre, Tzonis, 2003), the villa E.1027 comfort has to be assessed in accordance with the climatic conditions of the location where it is built, rather than with aprioristic prejudices.

\section{Choosing the right spot and the right orientation adapted to local climate}

Gray decided to select that specific spot at Cap Martin for its privileged mild climatic conditions (Fig. 4 and 5), and choosing an orientation to the Southwest overlooking the sea and Monte Carlo in the distance, while the French Alps summits tend to protect the Riviera from the undesired Tramontane and cold Mistral northern winds during the winter. The zig-zagging entrance sheltered by a wall was conceived to protect from those undesired winds (Espegel 2010, p. 138), in sharp contrast with the generous openings to the mild sea breezes during the warm season towards the sea.

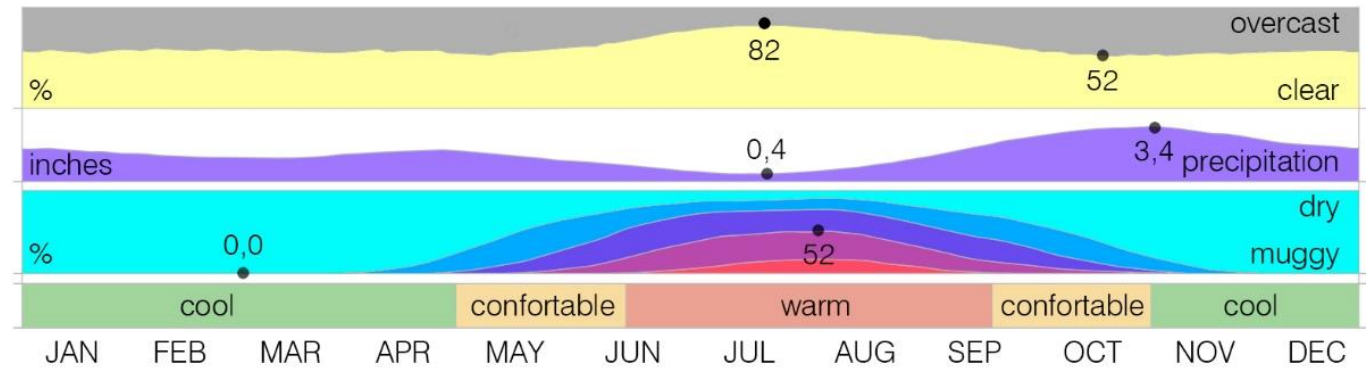

Figure 4. Average hourly weather in Roquebrune-Cap Martin Year-Round (shows the average hourly temperature colour coded into bands; shaded overlays indicate night and civil twilight. Data Source: Weather Spark).

Additionally, the little peninsula at Cap Martin protects the houses built on it from the eastern winds of the Mediterranean which are predominant and rather unpleasant in case of autumn storms. The main southern orientation of the house would benefit from natural ventilation throughout the warm season due to the dominant south winds. Although the purpose of the house was a vacation retreat, it ought to be noted that it was equipped for all seasons, including a heating system and a fireplace (Espegel 2010).

Ryan (2010, p.341) has noted that there are two facts that show design climatic consciousness. On the one hand, the $212,5^{\circ}$ orientation to the North of the main façade -comprised between the $135^{\circ}$ and $222^{\circ}$ cut-off angles for good orientation for the site- while the pre-existing terraces of the lemon grove are oriented $228^{\circ}$, very close to the winter solstice dawn azimuth and the summer solstice azimuth at dusk (Ryan 2010, Ibidem). Accordingly, the slight rotation and elongation of the main prism of the house to such precise orientation was not a casual decision, but rather a careful choice, with fundamental implications in the performance of the house. 


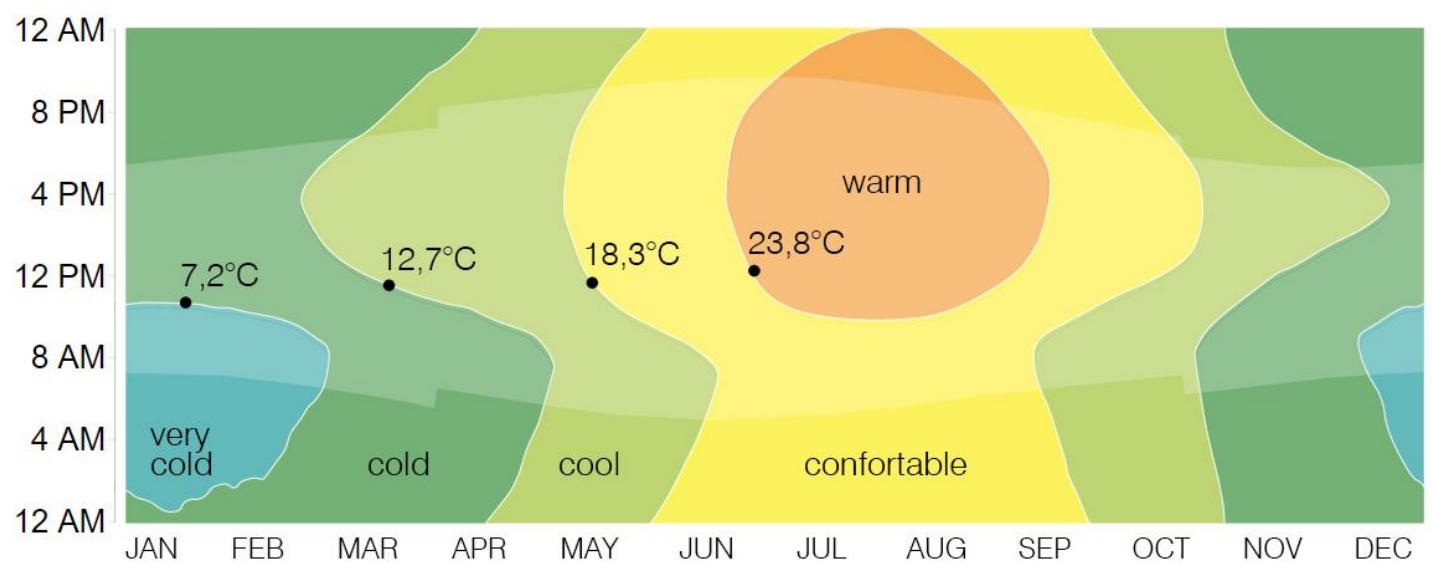

Figure 5. Average hourly weather in Roquebrune-Cap Martin Year-Round (shows the average hourly temperature colour coded into bands; shaded overlays indicate night and civil twilight. Data Source: Weather Spark).

As can be deduced from Fig. 6, the weather in Cap Martin is basically considered as Csa, Typical Mediterranean climate, according to the Köppen (Kottek et al, 2006) classification although its vicinity to the Alps contribute to generate a certain micro-climate. This implies temperate, humid rainy winters and warm, rather dry summers. Proximity to the Mediterranean Sea guarantees an average high level of humidity throughout the year.

\section{Nice Weather Conditions}

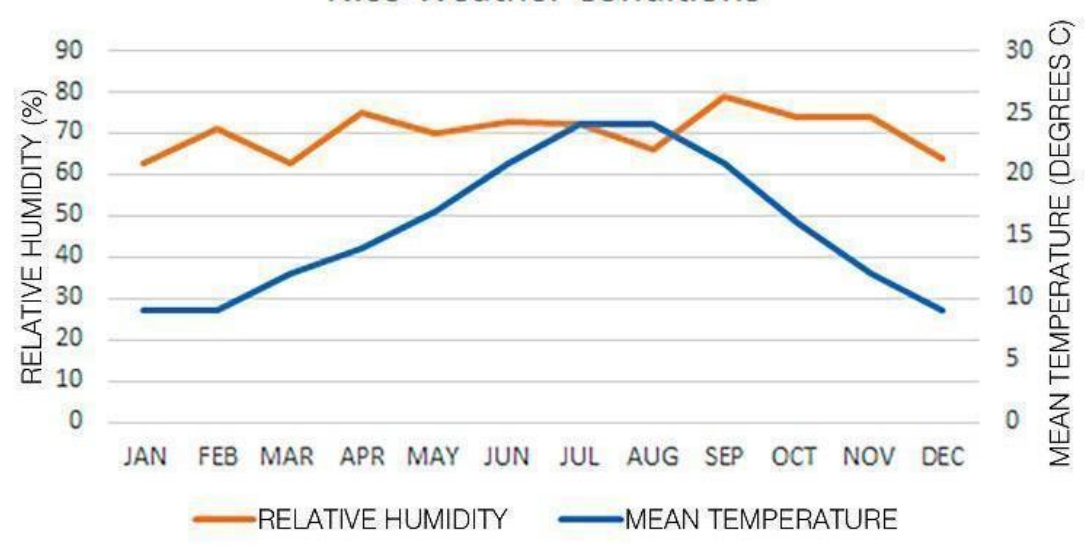

Figure 6. Weather data summary for Roquebrune-Cap Martin, Nice. (source: Climate Consultant)

\section{Research}

\section{Sun exposure}

Graphic evidence of the importance given to a climate conscious approach can be observed in a diagram of sun exposure and circulation routes that was drawn to convey the relation between the uses of the house and natural lighting (Fig. 7). This novel type of architectural diagram was also used by Gray sometime later for the design of her own house in Castellar, Tempe à pailla, between 1932-1934 (Moreno 2013, p. 130) suggesting her own concern with regard to understanding and studying the effect of natural lighting in her architectural designs. The fact that these diagrams show a special interest to simultaneously address sun trajectories and natural lighting in relation to circulation routes, space uses and levels of privacy -codified through differentiated line weights, continuous lines for the owners or dotted lines for the housekeeper movements-indicate a concern to combine architecture, sunlight and bodily experience (Constant, 2000, p. 114). Constant uses the idea of "choreographic approach" regarding Gray's sensibility to weave "relationships among the furniture, movement, and the human body" in an appealing blending of interior design, architecture, and the interactions of the human body to achieve the best comfort conditions. 


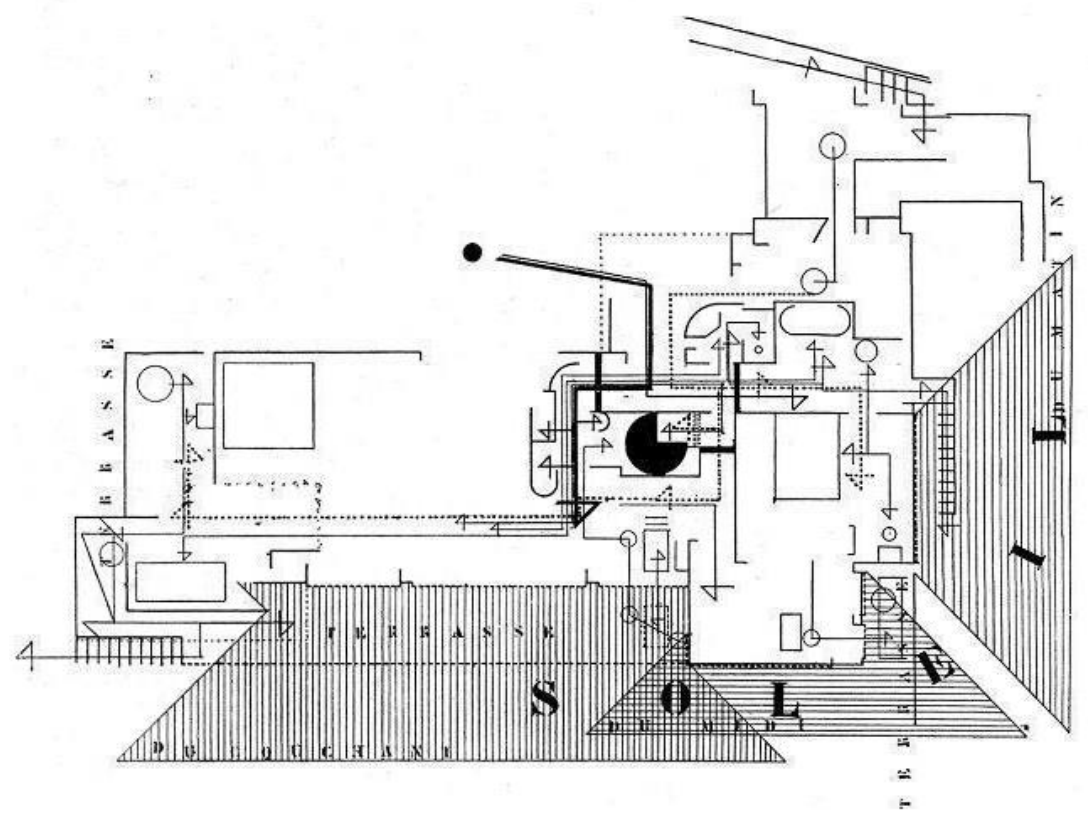

Figure 7. E. Gray and J. Badovici. Sun exposure and circulation routes diagram (Gray, Badovici 1929b, p.23).

The E.1027 is a good example of intertwining exterior and interior spaces, with recesses and corners carefully planned in relation to orientation and circulation. The elongated main façade of the building is dominated by the terrace enjoying the views and the sea breeze. This terrace, as mentioned before, is both covered and horizontally framed by sailcloth awnings suggesting the characteristic modern strip-window syntax when seen from the sea. However, the reality is more nuanced as the real window openings in the façade are, in fact, accordion glazed doors. They maximise solar gain in winter, when the awnings are retracted, offering passive solar heating as these openings basically face south, while allowing to open up a huge area of the house facing the sea in good weather. In fact, three different window types were sensibly designed for the E.1027 house and adapted to the different needs in accordance with their combination of ventilation control and modulation of sun exposure. Moreover, the recessed main façade, allowing for a veranda space, is placed in continuation with the studio of the main bedroom situated to the east side. Its façade plane is aligned with the awnings and handrail, but the window openings of the studio to the south façade needed a different detail, as they lacked the sun protection provided by the awnings running along this long terrace.

There is only one opening to the West, the most critical orientation during the warm season. This is a 'private' glazed access to the terrace for occasional guests lodged in the house. A screen of louvres has been superimposed over it but, in this case, unlike the horizontal openings used in the shutters, the louvres are vertical, to ensure adequate protection from the undesirable low setting sun to the west in the hottest days of the summer.

The analysis of the sun exposure carried out with Autodesk Revit and Sefaira software shows the designers' understanding of the sun's impact and its influence over the house's comfort performance. As can be seen in Fig. 8 and Fig. 9, the analysis of the influence of the sailcloth awnings shows its effectiveness both in the summer and during winter, as its geometry and overhang dimensions adapt to the sun angles in both seasons. 


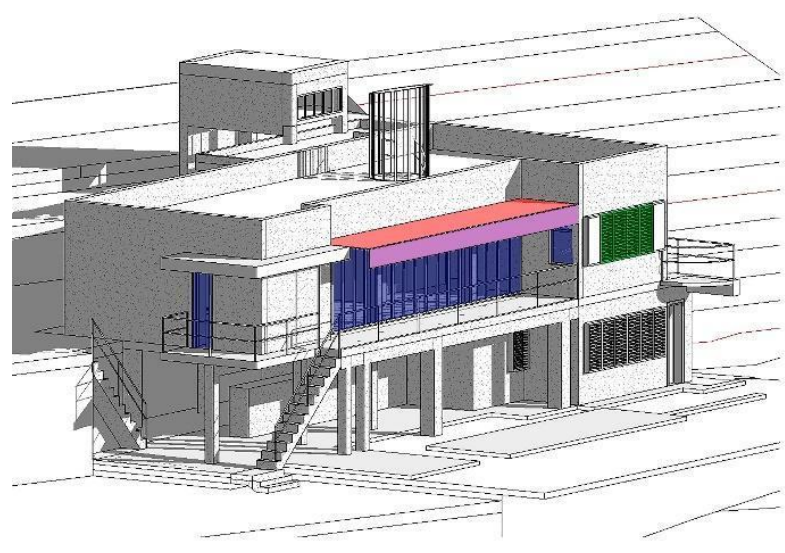

Figure 8. Villa E.1027 winter solstice 12:00.

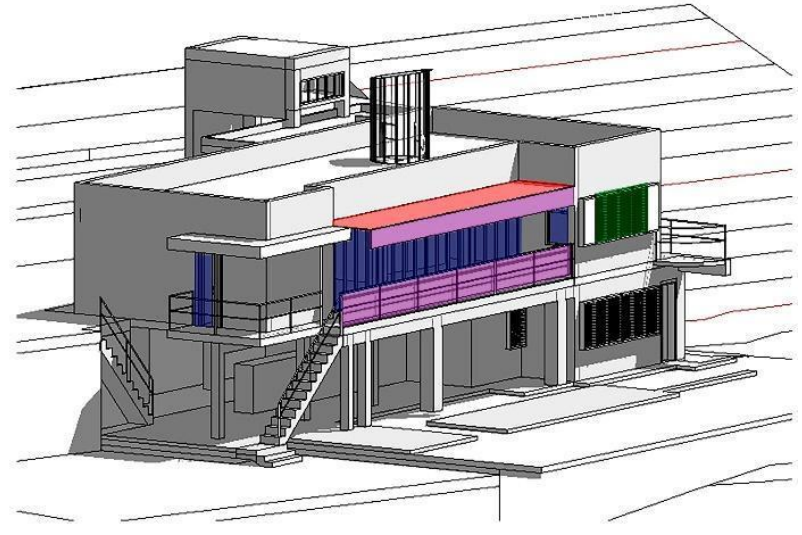

Figure 9. Villa E.1027 summer solstice 12:00. blue - glass, green - wooden slats, purple - vertical shading, red - horizontal shading.

The analysis of the sun exposure at the winter solstice 12:00 shows that even with the awning deployed, it does not avoid sunlight from entering in the main space of the house, allowing the penetration of the sun rays deep inside the living room. This situation allows a higher solar gain, contributing to raise the interior temperature at the time of the year when this is needed most, when the sun rays generously bathe the interior space illuminating the principal spaces of the house (multi-use living room, master bedroom and guest bedroom). The opening of the window shutters completes a highly illuminated situation with direct sunlight in all the rooms. The building orientation allows maximum illumination, as it can be seen in Fig. 11 at 12:00 at the winter solstice. Yet, at the summer solstice, at the same hour (Fig. 10), no sun penetrates inside the house thanks to the deployment of the canopy, the awnings and the shutters. We must stress the importance of the election of an effective passive solution in harmony with its dimensioning: both these critical factors embodied in Gray's and Badovici's ability to design an optimised climate conscious design as represented in the E.1027 project.

Bearing in mind that the E.1027 was principally designed as a summer house, the design solutions were adopted to respond to mild weather for a house facing the sea in the French Riviera. As can be observed in Fig. 9, at the summer solstice at 12:00 the awnings are perfectly located to block direct sunlight but at the same time allowing the sea views and providing ventilation if needed. In this case, the sun does not even reach the large accordion glazed-doors running along the living room thus avoiding sun radiation -and its inevitable solar gainsto the interior, at a time of the year during which, these gains would imply an undesired increase in the temperature.

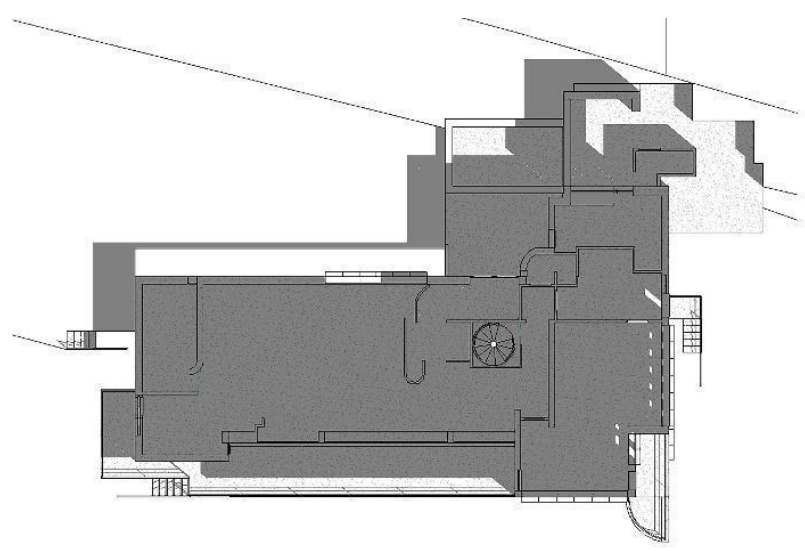

Figure 10. Villa E.1027 first floor summer solstice 12:00.

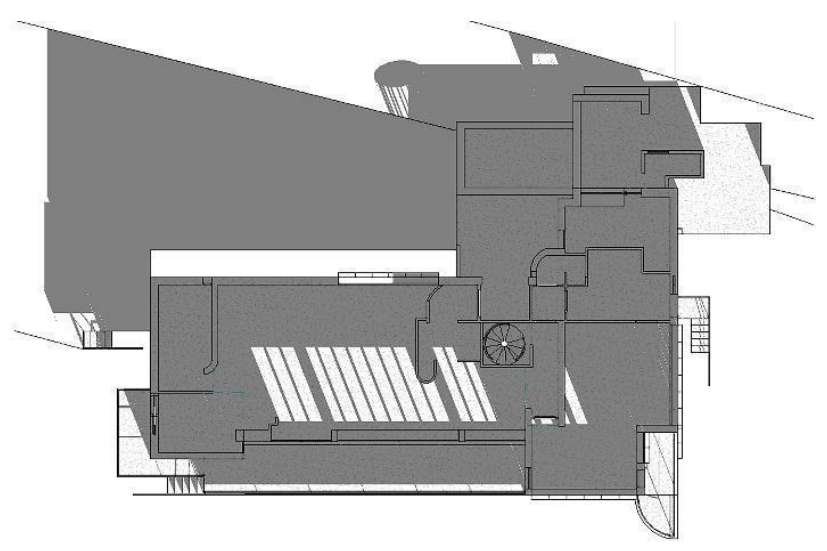

Figure 11. Villa E.1027 first floor winter solstice 12:00.

The awning deployed over the main living room window plays a very important role in the house's performance during the summer. As it is shown in Fig. 13, 14 and 15 the shading devices respond very effectively. In the analysis effected choosing July 15th, the warmest day according to weather data bases, the house provides a proper level of illumination and therefore temperature due to solar gains can be controlled. This solution, combined with the above-mentioned ventilation, provides the proper key feature to achieve a comfortable condition. The analysis of the illumination has been performed under the following scenarios (see the diagram in Fig. 12 to observe which of the windows corresponds with the letters A, B, C, or D): 


$\begin{array}{lllll}\text { July } 15^{\text {th }} 9: 00- & \text { A Closed } & \text { B Open } & \text { C Open } & \text { D Open } \\ \text { July } 15^{\text {th }} 14: 00- & \text { A Open } & \text { B Closed } & \text { C Closed } & \text { D Open } \\ \text { July } 15^{\text {th }} 14: 00- & \text { A Open } & \text { B Open } & \text { C Closed } & \text { D Open }\end{array}$

As it can be observed in Fig. 13, controlling sunlight through the window shades early in the morning reduces the intensity while allowing a proper illumination. The very important role of the awnings over the main living room window is revealed in Fig. 14 and 15. The use of this shading device decisively reduces the illumination in this main room during the warm season when the sun radiation intensity is greater while it allows its use without an intense summer light and contributes to raise the interior temperature in the cold season through solar gains.

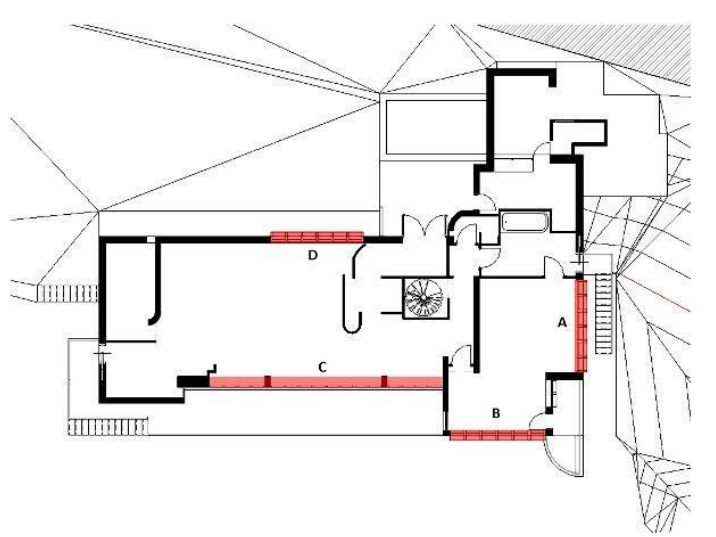

Figure 12. Windows scheme first floor.

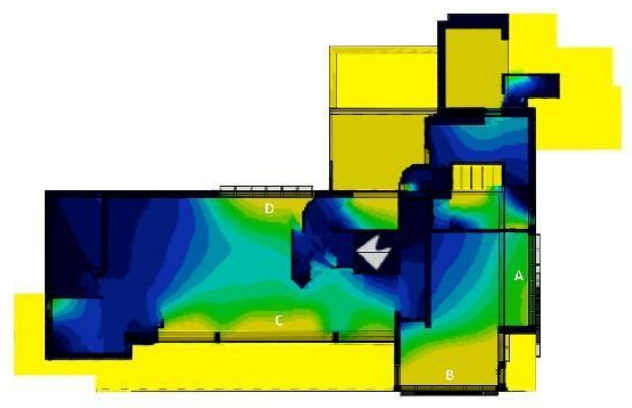

Figure 14. Villa E.1027 July 15th 14:00 with awnings. A: Open, B: Closed, C: Closed, D: Open Lux levels at 0,85 meters above the floor plate.

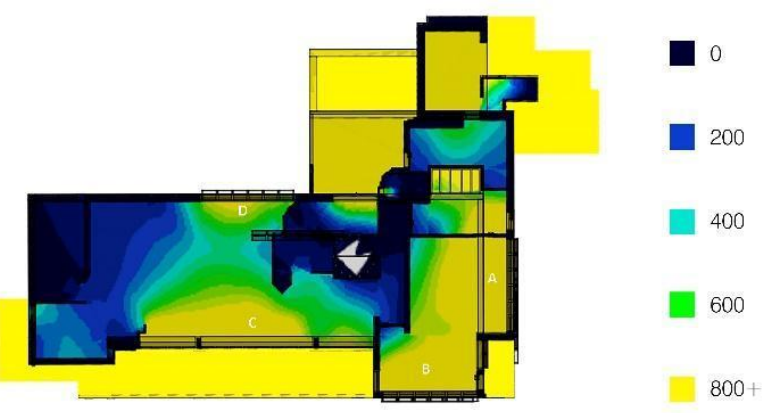

Figure 13. Villa E.1027 July 15th 9:00. A: Closed, B: Open, C: Open, D: Open Lux levels at 0,85 meters above the floor plate.

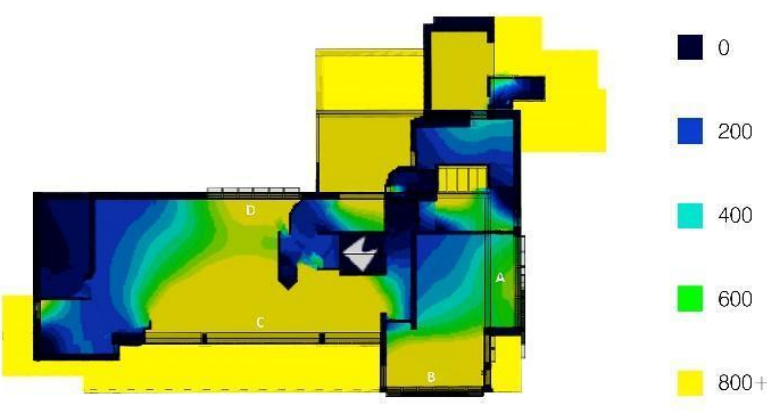

Figure 15. Villa E.1027 July 15th 14:00 without awnings. A: Open, B: Open, C: Closed, D: Open Lux levels at 0,85 meters above the floor plate.

On the other hand, it should be highlighted that from 18:00 till dawn the house orientation protects the main opening against sunlight coming from the west as it can be seen in Fig. 16, confirming the correct selection of the construction plot for the house and its orientation with regard to the sun trajectory. Finally, as it is shown in Fig. 17, on January $15^{\text {th }}$, the coldest day of the year according to weather data bases, the house has a proper illumination as the upper awning does not cast shadows towards the interior of the living room, and the shutters of the master bedroom windows can be partially opened, allowing the light to penetrate inside the house. Obviously, it is to be expected that the awning would be retracted in the cold season. The fact that its dimension allows for proper sun protection during the warm season while also providing -without the need for retraction of shading devices- for a generous sunlight inside the living room during the winter, when the solar gains are needed, accounts for the wise dimensioning of the passive protection elements. Additionally, as it can be seen in the section in Fig.18, the dimensions of the awnings in relation to the facade main opening are very adequately 
proportioned for the role they are intended for, in terms of solar protection and natural light control. In this comparative study of natural light and sun protection -with and without the awnings- it is easy to understand the refinement in the proportioning of these elements with regard to site and climate.

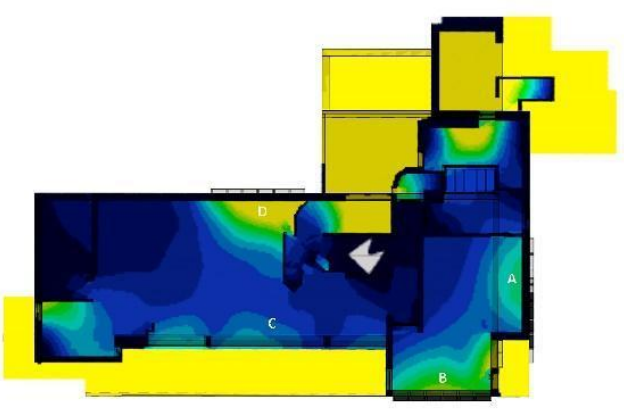

Figure 16. Villa E.1027 July 15th 18:00.

A: Open, B: Open, C: Open, D: Open Lux levels at 0,85 meters above the floor plate.

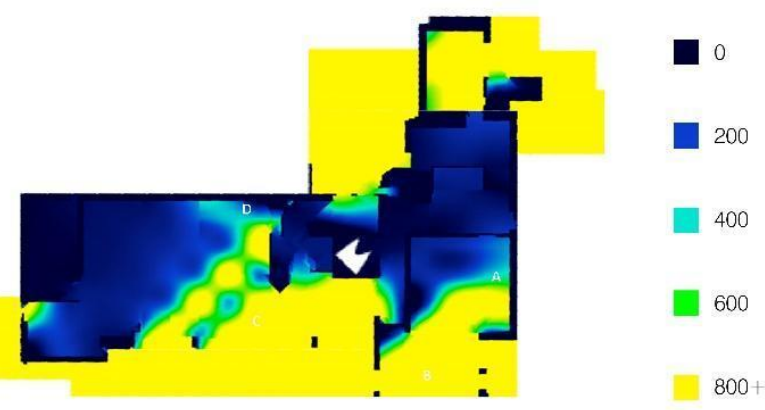

Figure 17. Villa E.1027 January 15th 16:00.

A: Open, B: Open, C: Open, D: Open

Lux levels at 0,85 meters above the floor plate.

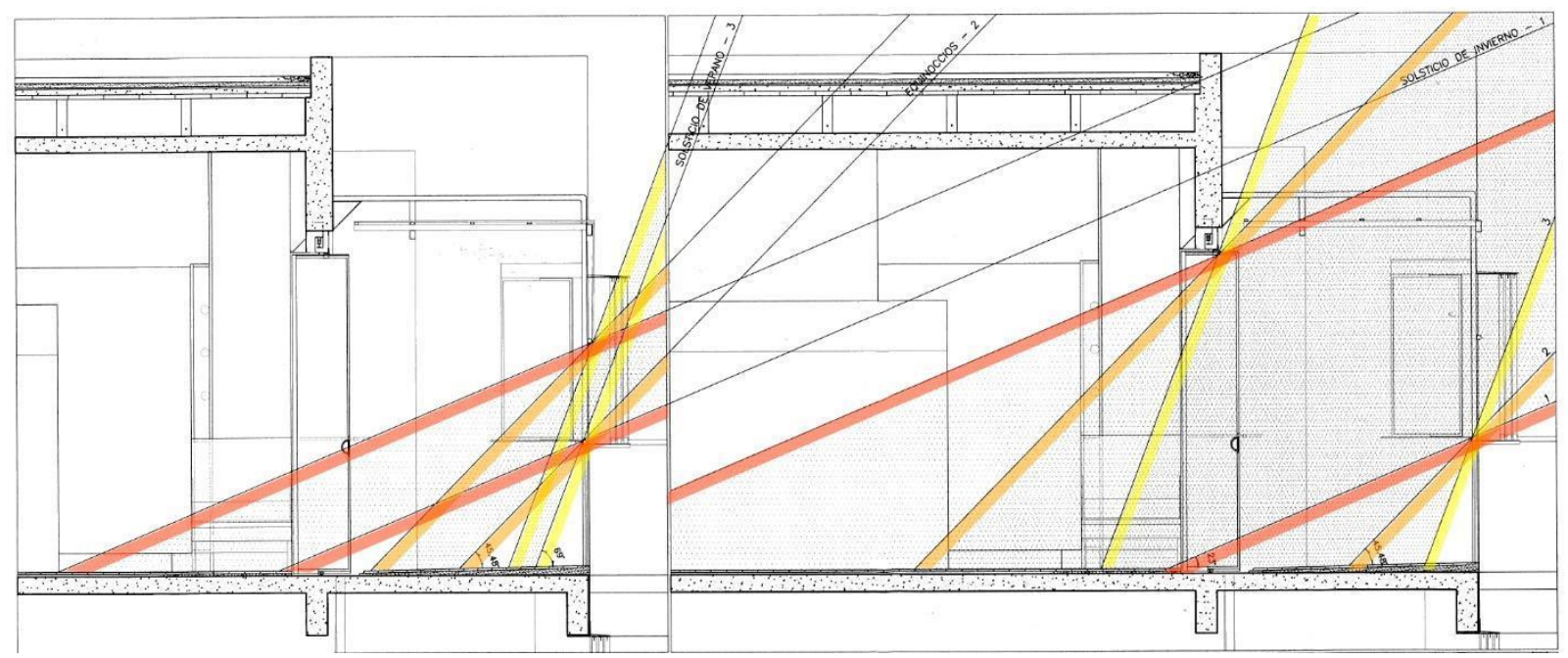

Figure 18. E. Gray and J. Badovici. Section detail study of natural interior lighting and sun exposure protection on the south façade with (left) and without awning (right) (Carmen Espegel, 1929b, Plan 54). Yellow: Summer Solstice; Orange: Equinox; Red: Winter Solstice (Authors).

Thus, the sun is neatly controlled throughout the year both, in terms of achieving comfortable natural lighting and temperatures through solar gains in the winter -as much as the latitude allows for-, and during the summer, when avoiding excessive sun radiation is vital to provide a comfortable range of temperatures inside the house while the fabric of the sailcloth awning still allows for a proper natural lighting (Fig. 19). The analysis carried out has additionally shown that the influence of the lower vertical awning (running along the handrail of the terrace) has no significant impact with regard to sun protection and interior temperature, although it contributes to diminishing the amount of light in the summer where the considerable exterior light intensity might need some nuanced filtering towards the interior. 


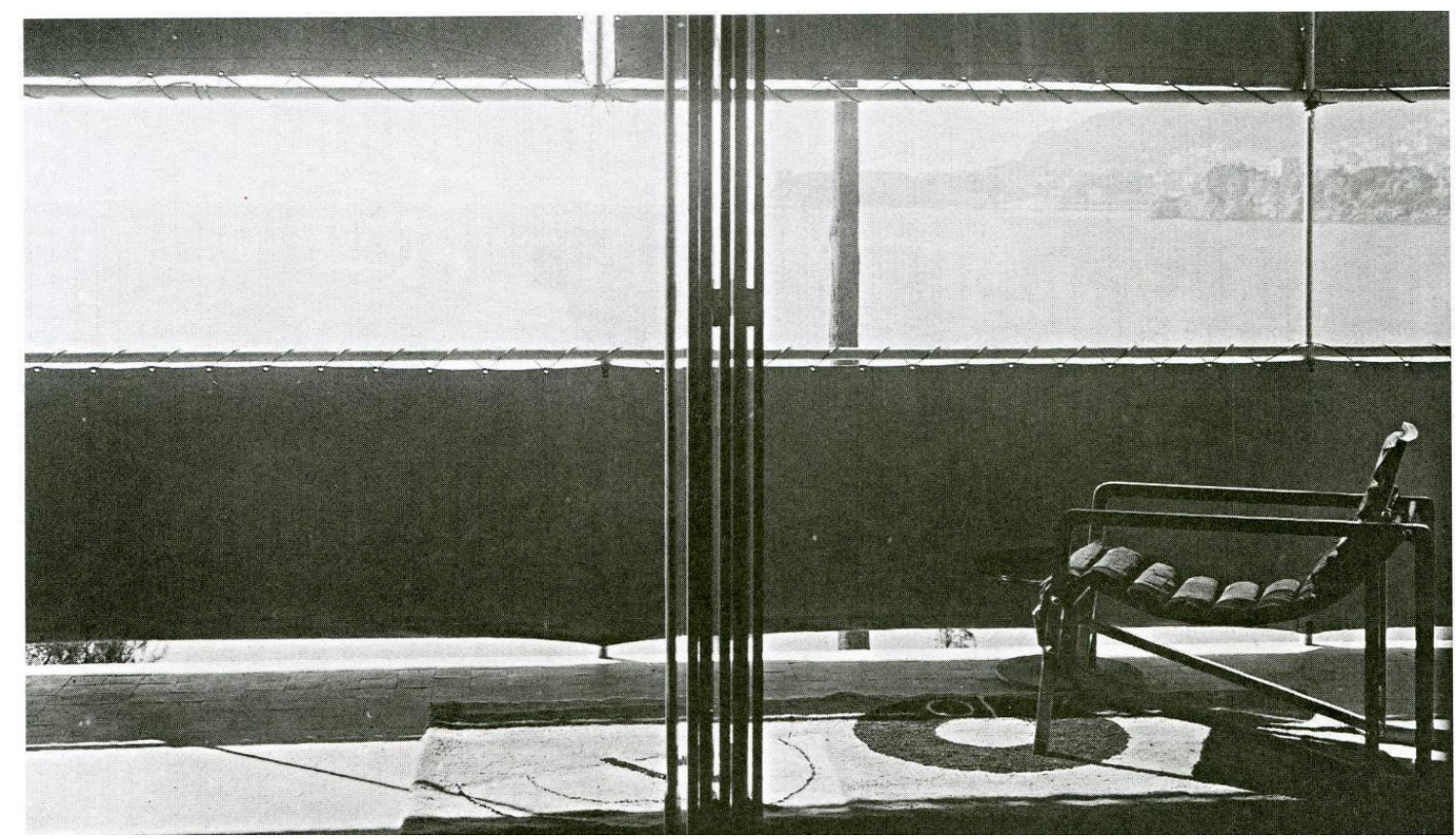

Fig. 19 View to the sea from the living room with canopy and vertical awnings deployed (Source: L'Architecture VIvant, Automne-Hiver, 1929).

All these carefully dimensioned passive design solutions are not a casual result of the overall design but rather a perfectly well-suited conception in terms of climate consciousness and comfort, extraordinarily balanced to control sun radiation, natural lighting, as well as sun or wind protection depending on the seasons. As Gray and Badovici wrote themselves, "The cloth canopy is made of four independent pieces to resist the strongest mistral winds; it allows cool shade in the summer when the sun is blazing, and full exposure to the sun's heat in winter, while being sheltered from the wind." (Gray, Badovici, 1929, p.30). This statement written in their description of the project is crystal clear about their awareness of the climate and accounts for their extraordinarily sitespecific design.

If the maximum illumination values for the living room during the equinoxes and the solstices with the awnings deployed are compared (Fig. 20), there is basically a regular amount of light in the interior throughout the year. This graph effectively shows the optimisation of the design in terms of the balance between solar protection and natural lighting.

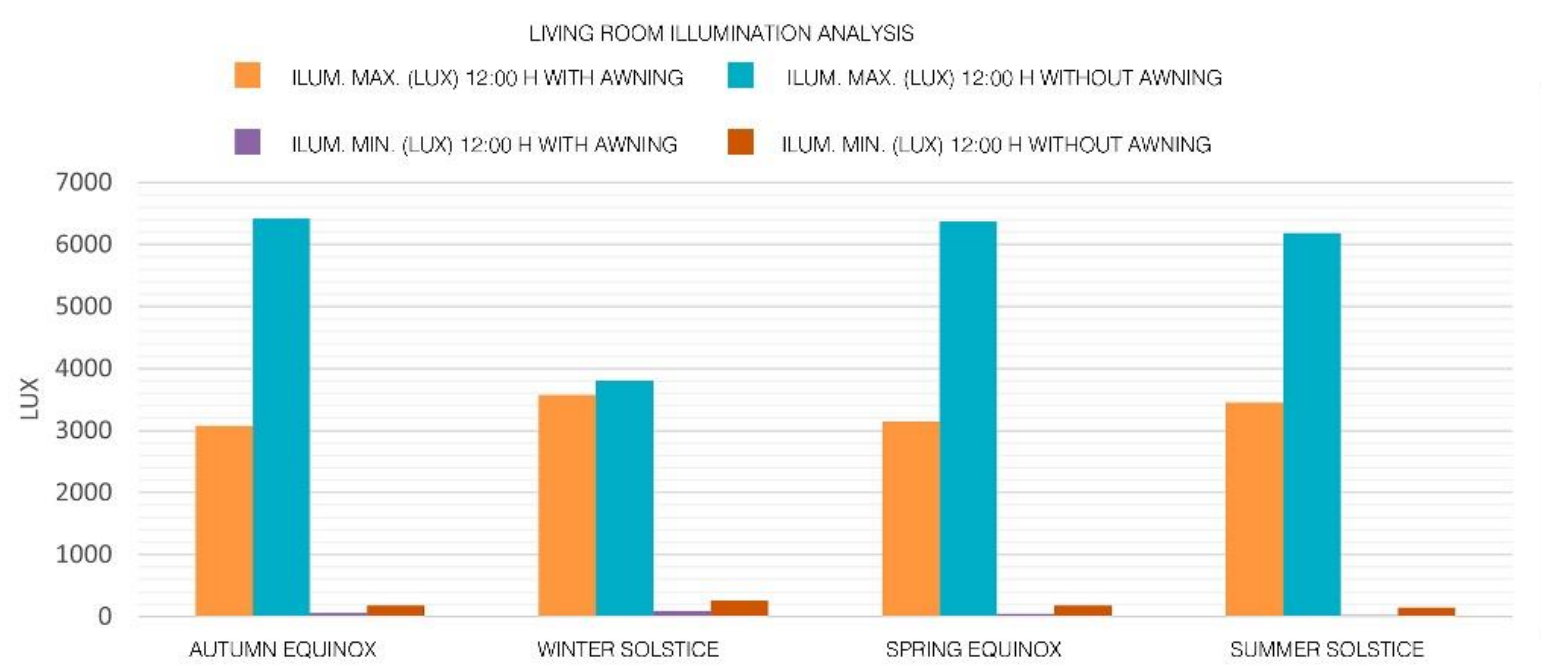

Figure 20. Villa E.1027 Maximum and minimum illumination.

\section{Natural ventilation}

The house is basically a long narrow prism facing close to the south, an orientation that contributes to 
maximise cross-ventilation to improve thermal comfort due to the prevailing breezes in the warm season. Long accordion glazed-doors (Fig. 21) run along most of this main façade, while it is dependent on the strip window on the northern façade to enhance the cross-ventilation effect. In fact, excepting the service bedroom, the workshop and utility services area, all the rest of the rooms have their independent cross-ventilation (Espegel 2010, p.136). The design of the large glazing to the south -sliding and pivoting-allows its full operation along the entire glazed wall opening. It is almost like a drapery that facilitates "an uninterrupted expanse; the interior can thus open directly to garden and sea" (Constant 1994, p.274). Through it, a relatively narrow long terrace running along the south facade is accessed. It overlooks the sea benefiting from the cool breezes in the good weather. The sailcloth awnings and membranes that wrap this space serve to protect the exterior from undesired sea breezes when it gets too windy, thus contributing to modulate natural ventilation in addition to the generous mentioned glass panes to the south. The awnings, considering their enclosing potential for the terraced space, not only serve as a protection against the sun radiation in the summer, but also as an effective protection from the sea breezes that can eventually get rather unpleasant.
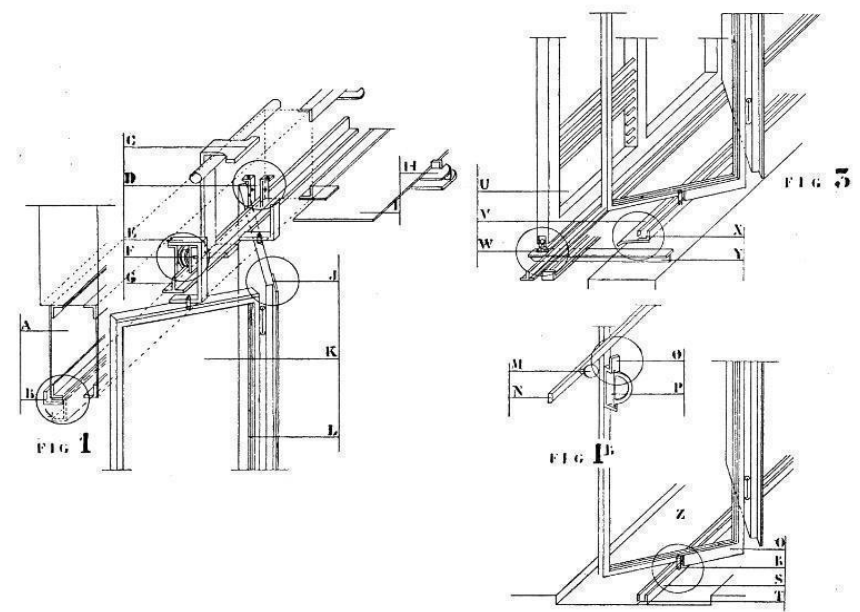
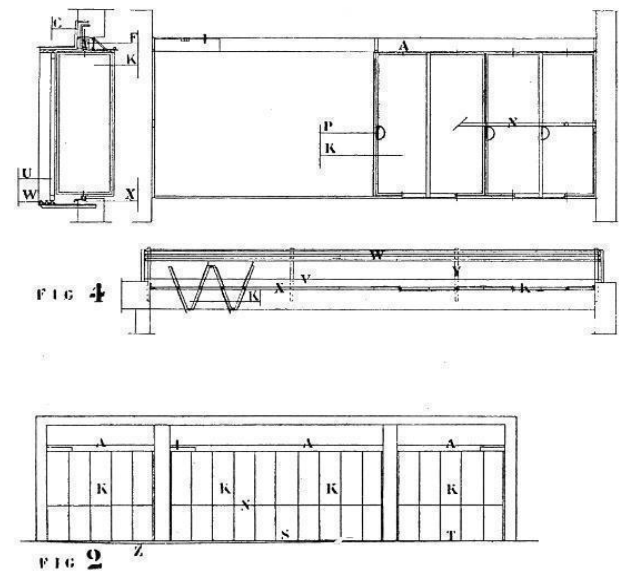

Figure 21. Elaborate details of master bedroom window and accordion glazed doors in the living room (Badovici held a patent for it), E. Gray and J. Badovici. (Gray, Badovici 1929b, p.24).

The windows of the main bedroom-studio oriented to basically east and south, respectively, were patented by Badovici himself, with shutters inspired in the vernacular Niçoise shutter allowing different degrees of ventilation, depending on the intensity of the breeze (Constant 1994). This carefully detailed design allows combining solar protection and additional breeze regulation thanks to the horizontal pivoting of the lower section of the shutters, inviting the dweller to take action in order to improve thermal comfort. (Fig. 22). Gray and Badovici themselves wrote about them: "Otherwise, all current combinations lead to the same result: insufficient ventilation when the shutters are closed. Our method leaves a large area for the free passage of fresh air while blocking excess of light" (Gray, Badovici 1929b, p.28). 


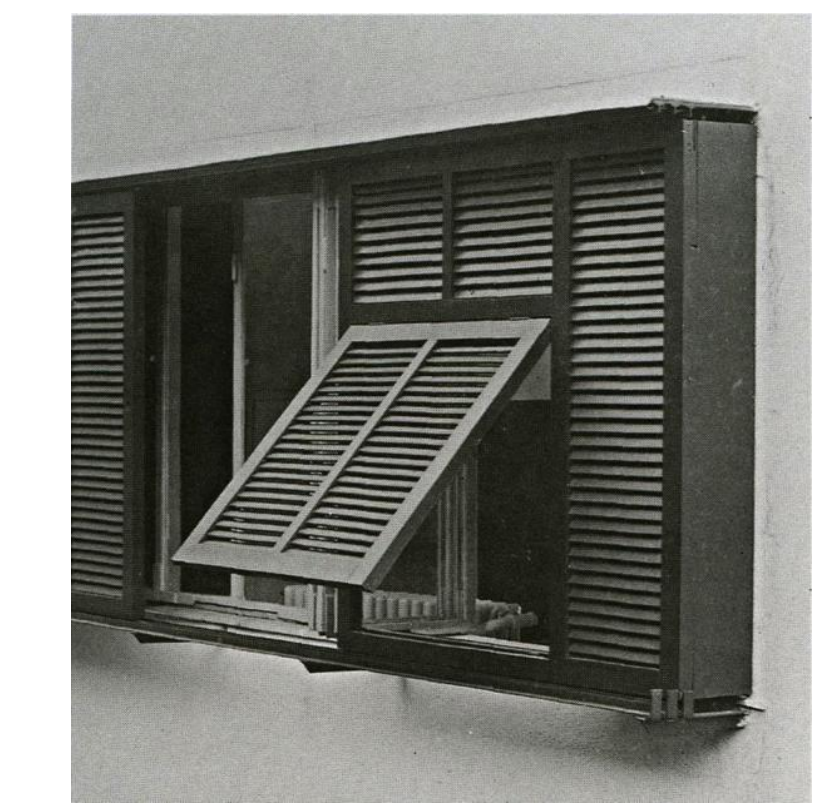

Figure 22. Elaborate window with horizontal pivoting Nicose shutters

(Source: L'Architecture VIvant, Automne-Hiver, 1929).

In a different yet complementary approach, two other design strategies are followed to cool the building in the warm season by means of natural ventilation. A staircase connects the lower level all the way up to the roof, enhancing stack ventilation even when wind speed is low: this effect is maximised as the height between air inlet and outlet comprises the full height of the house. Its shaft is larger than the staircase, thus allowing for light as well as ventilation (Gray, Badovici 1929, p. 34). This helps to cool down the temperature of the high thermal mass interior surfaces at night, and allows them to act as a heat sink the following day when the temperature rises. Additionally, the fact that the main body of the building is raised over pilotis allows for its extra ventilation, increasing the surface of convection and its shade below this body of the house.

The influence of these architectural solutions to provide thermal comfort through natural ventilation during the day has been evaluated by a basic CFD analysis using DesignBuilder. As it can be seen in Figs. 23, 24, 25 and 26 , the building orientation and the strategic situation of the openings in the living room respond to the designer's intention, providing enough flexibility to open and to close the windows depending on the varying intensities of the sea breeze. The possibility of generating cross-ventilation opening the front window offers enough combinations to achieve comfortable temperatures in the living room. The analysis of the operative temperature, and the relative humidity in the different scenarios with the Fanger's PPD, shows the importance of this cross-ventilation strategy to achieve thermal comfort. As can be seen in Figs. 23 and 24, the flexibility of the design solutions allow for the adaptation of the house to weather changes, something of great importance in a house facing the sea with considerable wind speed and temperature fluctuations. 


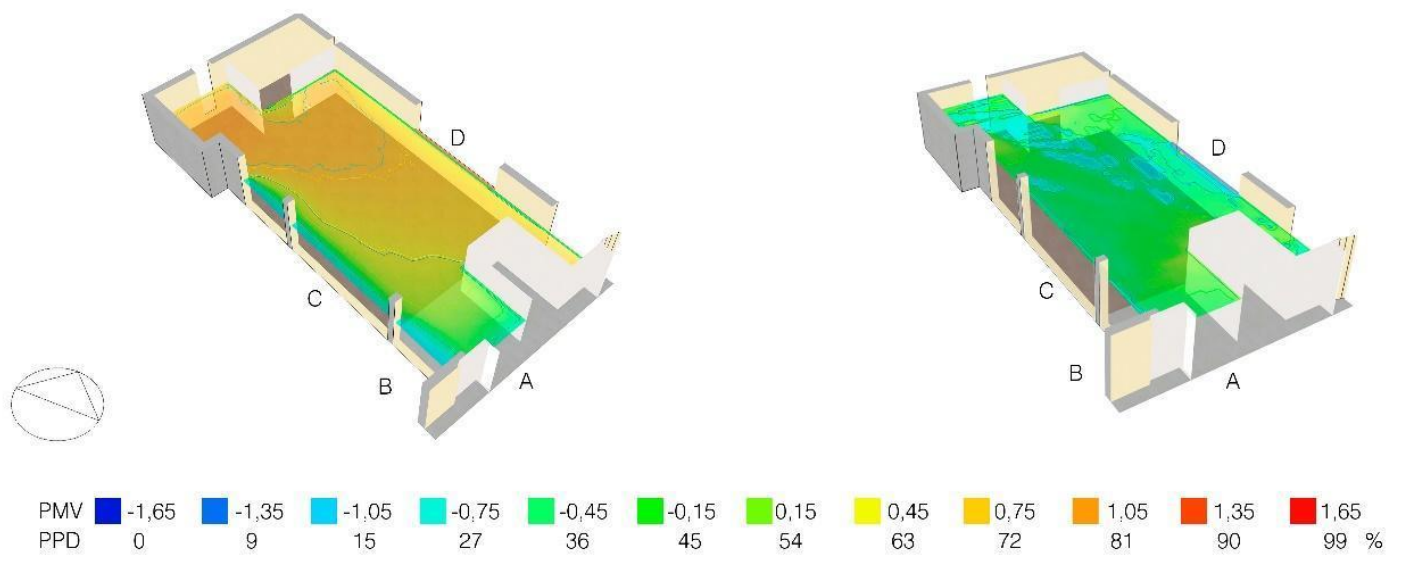

Figure 23. July 15th Basic CFD analysis PMV PPD (front (C) and back (D) windows open).

Figure 24. July 15th Basic CFD analysis PMV PPD (front window (C) closed and back window (D) open).
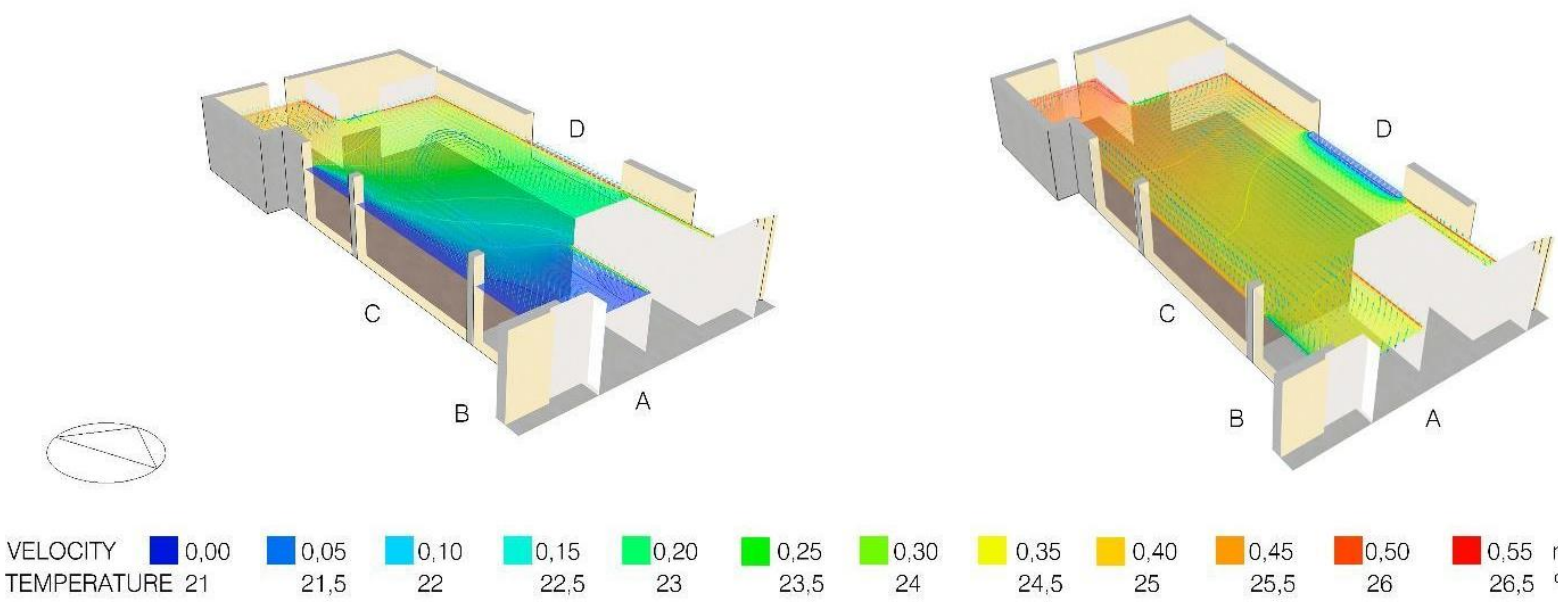

Figure 25. July 15th Basic CFD analysis wind speed and temperature (front (C) and back (D) windows open).

Figure 26. July 15th Basic CFD analysis wind speed and temperature

(front window (C) closed and back window (D) open).

Uncomfortable situations when the sea breeze becomes intense, or the relative humidity rises can occur in a house facing the sea. In this sense, the possibility of providing cross-ventilation, or protecting from the direct wind, becomes a key factor to improve the indoor thermal conditions in different circumstances. Fig. 27 shows the analysis performed during the warmest day of the summer, evidencing that opening the front window to the sea without ensuring cross-ventilation through the back window produces an uncomfortable scenario as both relative humidity and temperature rise. This situation is mitigated when direct wind from the sea is blocked, but ventilation is still provided through the back window of the living room. Finally, the desired state would be the one that provides a proper ventilation by opening both windows. In this scenario relative humidity is kept under control, while temperature decreases. However, this situation finds its limit when the sea breeze blows strong, and the average wind speed goes up. In such circumstances, to keep the house within comfort values, windward openings ought to be closed, while the other ones should remain open. Gray and Badovici also considered the awnings as a tool to reduce wind speed, allowing the windows to be opened if the sea breeze was not too strong (Gray, Badovici, 1929b, p. 30). 
TEMPERATURES AND RELATIVE HUMIDITY

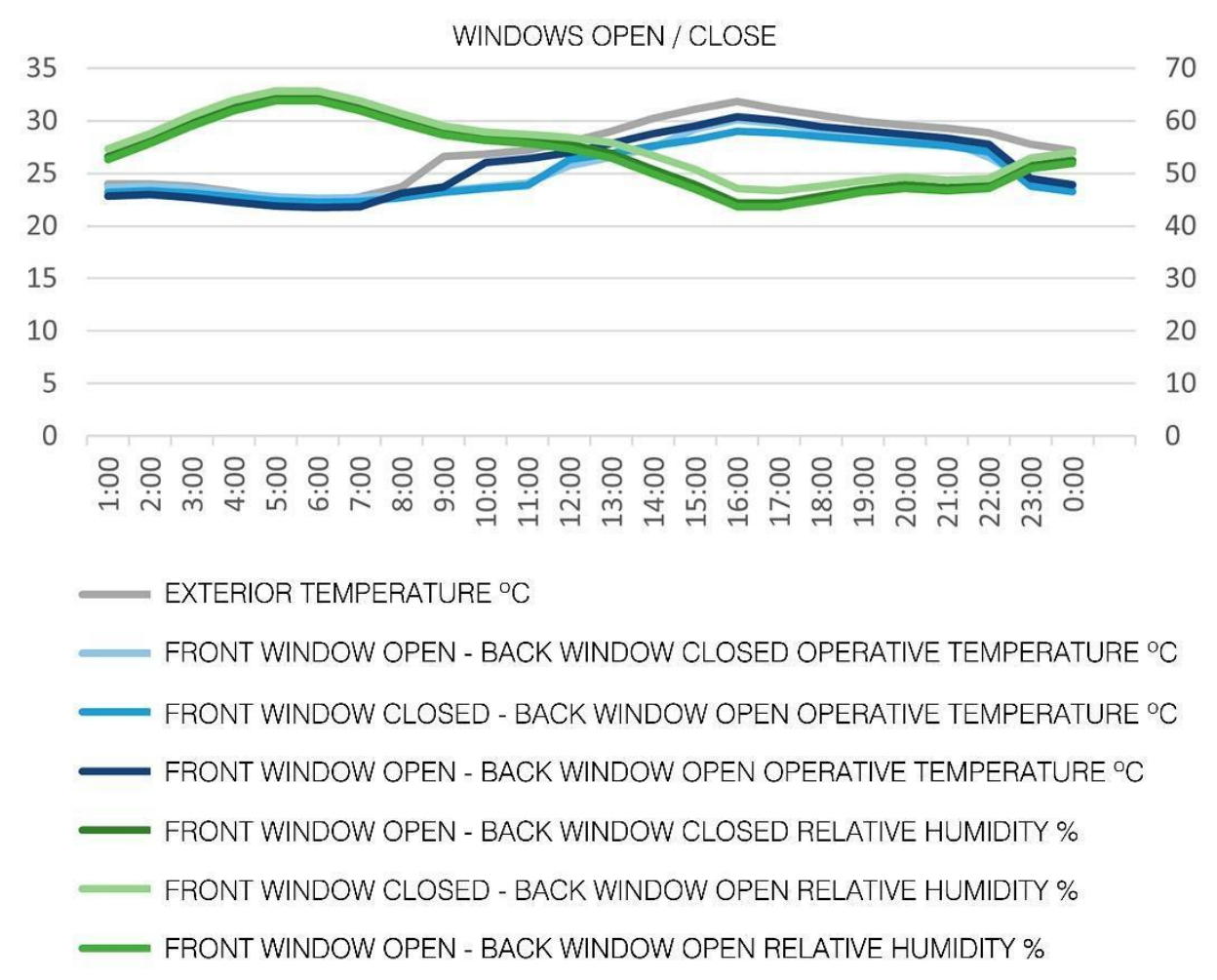

Figure 27. July 15th Analysis of temperature and relative humidity.

Fanger's PPD, Fig. 28, shows that if the main southern window is open but the back window is closed, from 13:00 till almost 21:00, the percentage of dissatisfied people would be over the 10\% limit defined by ASHRAE. Closing the main window facing the sea decreases the relative humidity in the interior of the living room, and therefore thermal comfort may increase provided the back window is opened. If both windows are open, however, then the percentage of dissatisfied people is, accordingly, reduced, but it may produce dissatisfying situations as the wind speed increases. Obviously, our comfort sensation is dynamically dependent: additionally, the wind speed must also be considered relative to hygrothermal comfort values.

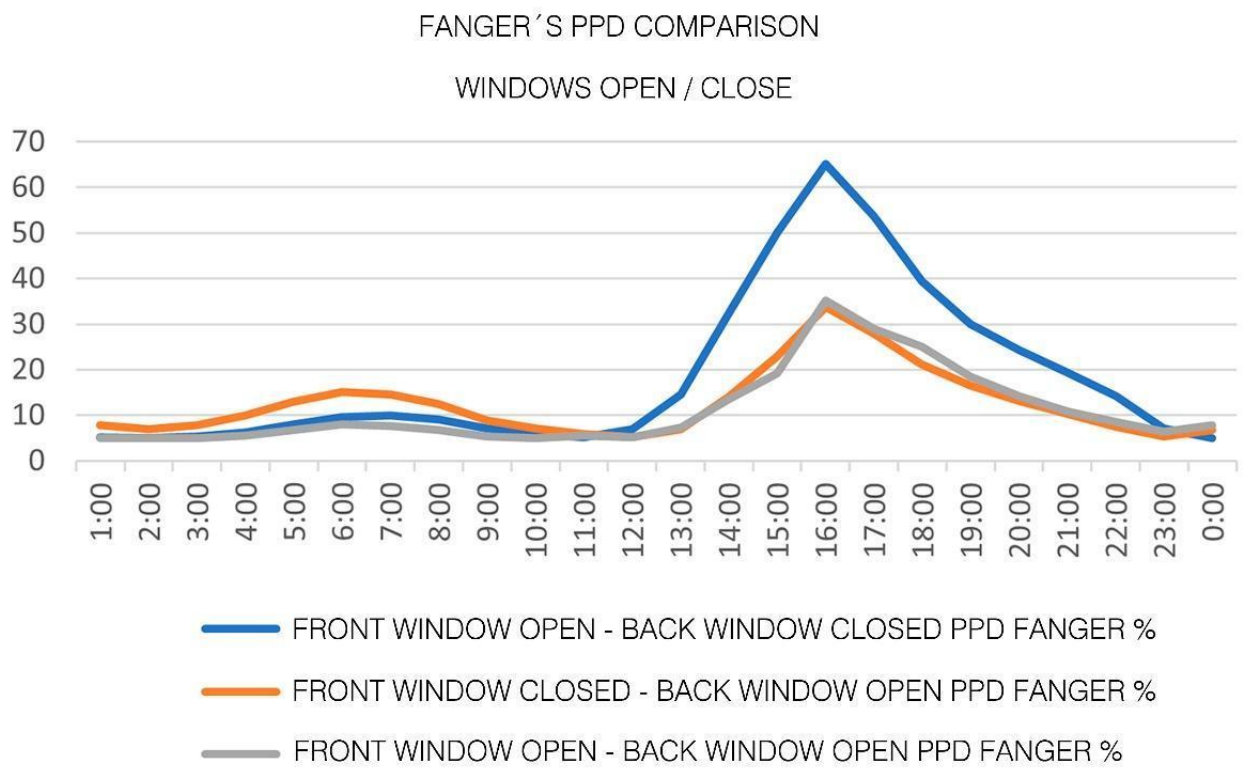

Figure 28. July 15th. Fanger's PPD analysis. 
It is worth underlining the understanding that Gray and Badovici show through their design, particularly focusing on the elements involved in the house's comfort performance, especially considering the fact that the key issues for this kind of climate are solar protection, ventilation, and natural lighting. The building's orientation, the facade openings, and the conception of a multi-layered skin in the openings show a conscious control over the parameters to be considered when aiming to optimise thermal control results. All of these passive solutions account for an elaborate design to control sunlight, ventilation and solar protection in a multi-layered strategy (Constant 1994, p.274). Even the fact that the window type with orientable shutters is also used in the northern opening of the living room, but -although being on the upper floor-its overhang is only $20 \mathrm{~cm}$. shows their subtle control over the dimensioning. They even wrote about the different aspects these windows served to control, suggesting their analogy to a "camera shutter" (Gray, Badovici, 1929b, p.31-32).

\section{Thermal Comfort Analysis}

One of the architects' concerns was the adaptation of the house to the local climate and the extent to which the design was flexible enough to adapt to the shifting weather conditions. The flexibility of the shading devices and the variety of windows were intended to provide the proper answer to these concerns. The analysis of the house with modern simulation tools reveals that both Gray and Badovici knew very well what they were doing: achieving with the E.1027 house a prescient modern design with significant adaptive features that proved to be very comfortable. The fact that Le Corbusier -despite having built his own Cabanon just meters away on that narrow strip of rocky plot-often spent time at E.1027 after Badovici's death is testament to this. (Marcos 2011, p.282) This after he used a personal friend to buy it at auction must certainly be attributed to the house's efficient thermal comfort performance.

In our studies of E.1027 presented here in this article, the yielded results with the simulation tools for the house - annual daily and hourly- with DesignBuilder have been used to perform the predicted analysis of thermal comfort under three methods: Givoni's, Fanger's, and the ASHRAE 55 Adaptive Method. In all of them, the thermal comfort limits correspond to the values proposed by the ASHRAE 55 regulation. The analysis done under Givoni's and Fanger's method is presented in a psychrometric chart aided by a web app tool, Psychrometric Chart (Marsh 2018). Hourly data are introduced into the app so that the comfort and extended comfort zones can be analysed by both Givoni's and Fanger's methods to evaluate how and to what extent the different design solutions impact the house's performance, observing the time in which the house is under a predicted comfort situation or an extended comfort situation without the use of conditioning systems.

Firstly, it must be noted that the nearest coastal meteorological base with available .epw files is Nice, only $25 \mathrm{~km}$. away from the location. As shown in Fig. 29, the regulation ASHRAE 55 defines the comfort zone within a temperature range of $20-24{ }^{\circ} \mathrm{C}$. In the period between June and September, the exterior mean temperature is within this range. Additionally, there is a percentage of hours that fall within the comfort values in May, and to a lesser extent in October and in March; this extends the comfort temperature zone over the mentioned period.

\section{Nice Comfort Temperature}

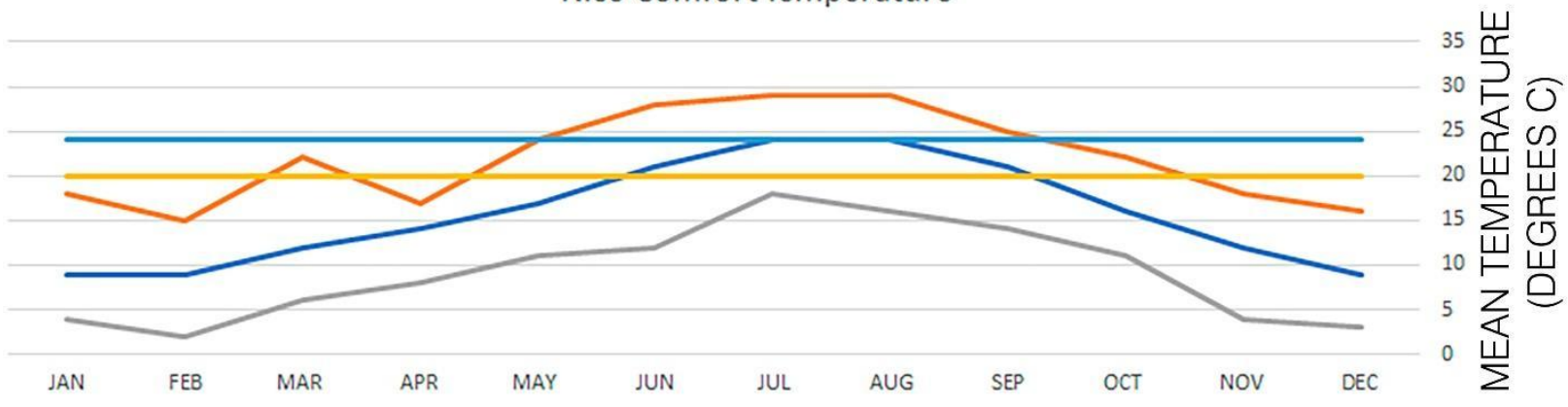

—DESIGN HIGH TEMPERATURE — MEAN TEMPERATURE

—DESIGN LOW TEMPERATURE — COMFORT ZONE LOW —COMFORT ZONE HIGH

Figure 29. Comfort Temperature (Data Source: Climate Consultant).

The mean Relative Humidity is over $60 \%$ throughout the year, and it is especially high during the summer (70-80\%), when winds blow predominantly from the sea. High temperature with medium high relative humidity 
implies a higher thermal sensation and a reduction in the possibility of using the exterior climate conditions to generate indoor thermal comfort conditions. With these weather conditions, vernacular architecture has addressed sun exposure and ventilation to provide indoor thermal conditions during most part of the year, something confirmed by the above-mentioned methodologies.

As it can be observed in Fig. 30, based on uploaded and processed climatic hourly data, combined with Givoni's comfort zones on the psychrometric chart, show that most predicted thermal comfort values fall within either the comfort or the extended comfort zones of the chart. These are between $20-27^{\circ} \mathrm{C}$ dry bulb temperature and $20-82 \%$ RH with no energy input, and the summer extended comfort zone stretches to $32^{\circ} \mathrm{C}$ with the aid of natural ventilation and up to $37^{\circ} \mathrm{C}$ with mass cooling. On the other hand, the winter extended comfort zone falls to $12.5^{\circ} \mathrm{C}$ with use of internal heat gains and $8^{\circ} \mathrm{C}$ when passive solar heating is further used with $20-80 \%$ relative humidity. These results confirm that the E. 1027 has the proper passive solutions to adapt to the location's climate conditions and to provide adequate thermal comfort in the period of the year that the house was planned to be used.

At the same time, Fig. 30 -overlapping the Fanger's method over the same psychrometric chart- reveals that the accomplishment of the PMV limits defined by ASHRAE 55 implies the need of natural ventilation to provide comfort conditions displacing the comfort zone slightly to the warm side of the chart. The conditions considered in the calculation of the PMV are those that could be expected in a house with a relaxed low activity level.

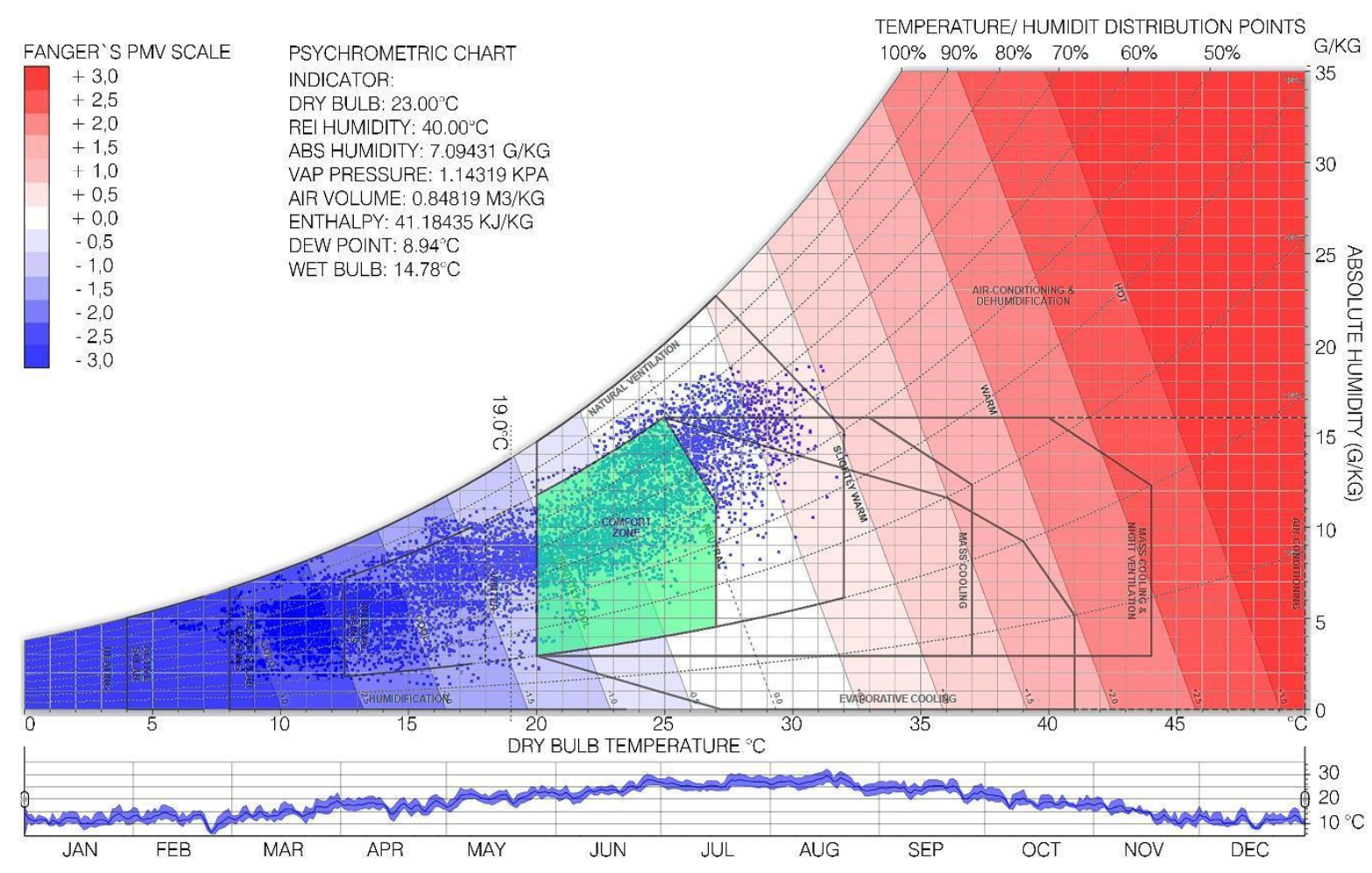

Figure 30. Villa E.1027 performance. Bioclimatic chart using Givoni's and Fanger's methods. (Fanger's PMV values are graphed with a range of colours from blue to red including the PMV numerical values).

Nevertheless, the importance of the sun exposure and protection in combination with adequate ventilation regarding the building's simulated performance under Fanger's method can be observed in Fig. 31. The evaluation of the impact of these passive solutions reveals that both the coordinated control of sunlight and the use of ventilation improves the predicted house performance, especially during the very warm period of the year. Reducing ventilation takes the house out from the upper PMV limit defined by ASHRAE, something that is also consistent with the shading system. 


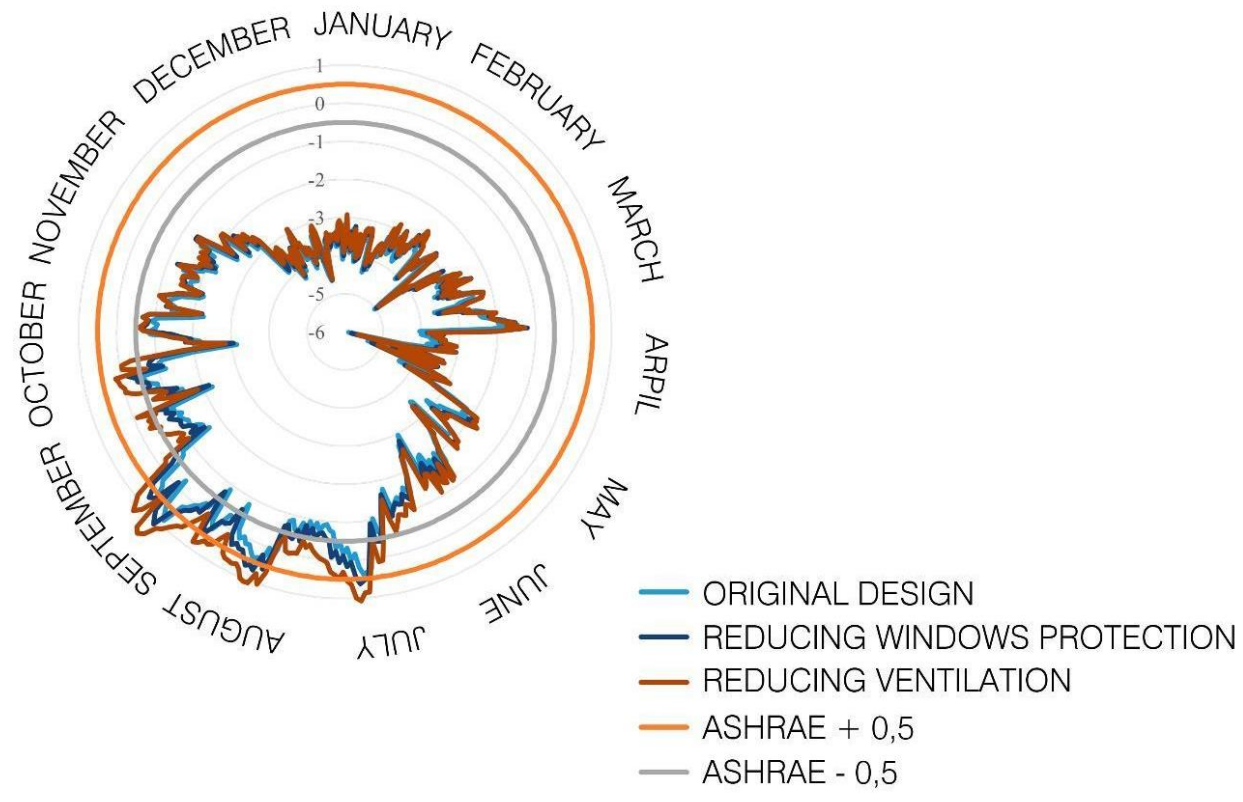

Figure 31. Villa E.1027 original design performance yearly Fanger's PMV with the limits defined by the ASHRAE 55 regulation comparing the impact of ventilation and sun exposure control.

However, the E.1027 design fits into the scope of the Adaptive Method defined by the ASHRAE 55 regulation. This method defines an acceptable thermal environment only for occupant-controlled naturally conditioned spaces that meet some criteria. These criteria are, however, limited in comparison to what the E.1027 really provides. There is no mechanical cooling, the occupants metabolic rate ranges from 1,0 to 1,5 , the occupants are free to adapt their clothing to the indoor and/or outdoor thermal conditions and the mean outdoor temperature ranges between $10^{\prime} 0^{\circ} \mathrm{C}$ and $33^{\prime} 5^{\circ}$. Fig. 32 shows that the yielded results of the simulation provide a daily average operative temperature that falls within the limits defined by ASHRAE from May until October.

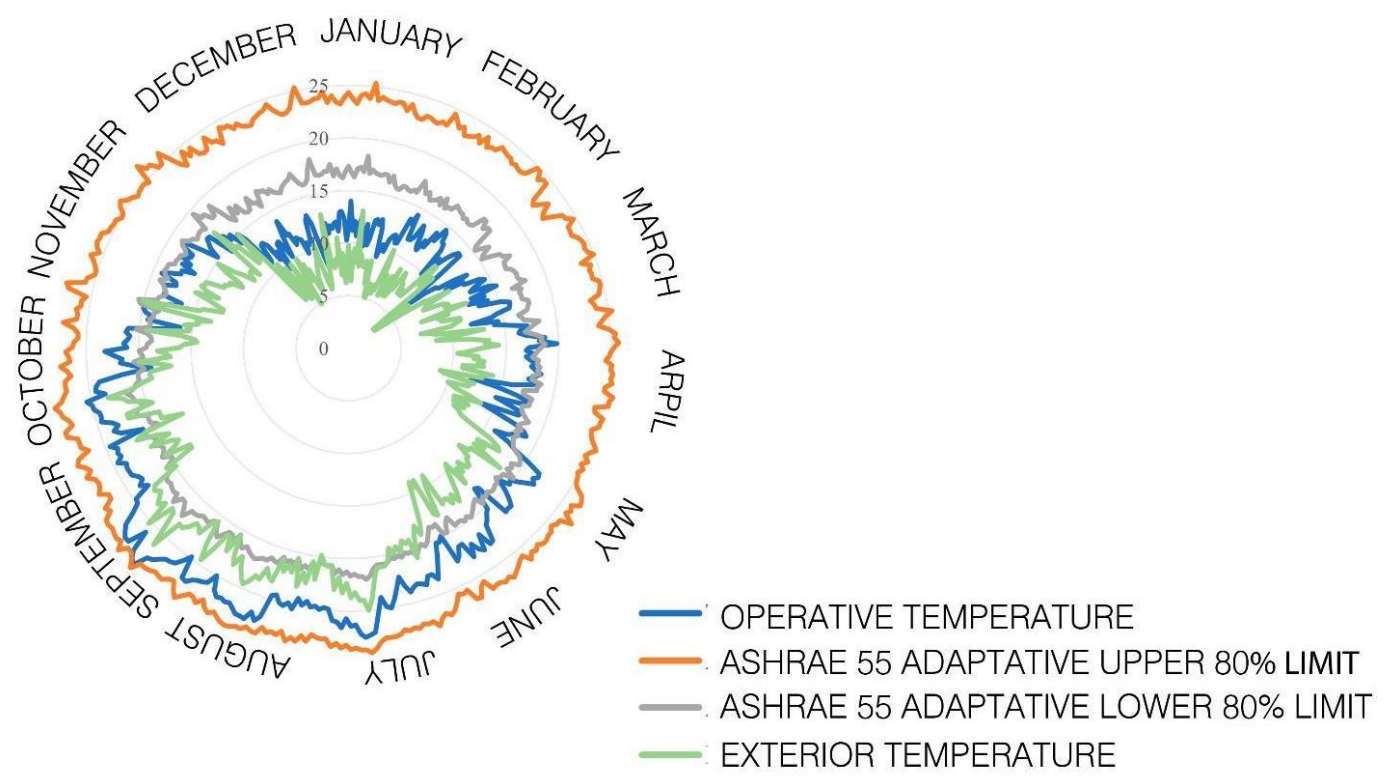

Figure 32. Villa E.1027 evaluation of thermal comfort through the ASHRAE 55 Adaptive Method.

As shown in Fig. 33, the evaluation of the annual hourly simulation yielded results proving that the house has an operative temperature between the upper and the lower limits defined by ASHRAE 55 during 2.736 hours per year that account for $31,53 \%$ of its annual use. When this figure is considered together with the expected 
warm period, from June $1^{\text {st }}$ till October $31^{\text {st }}$, it implies that $61,96 \%$ of that time the house is under operative temperature limits.

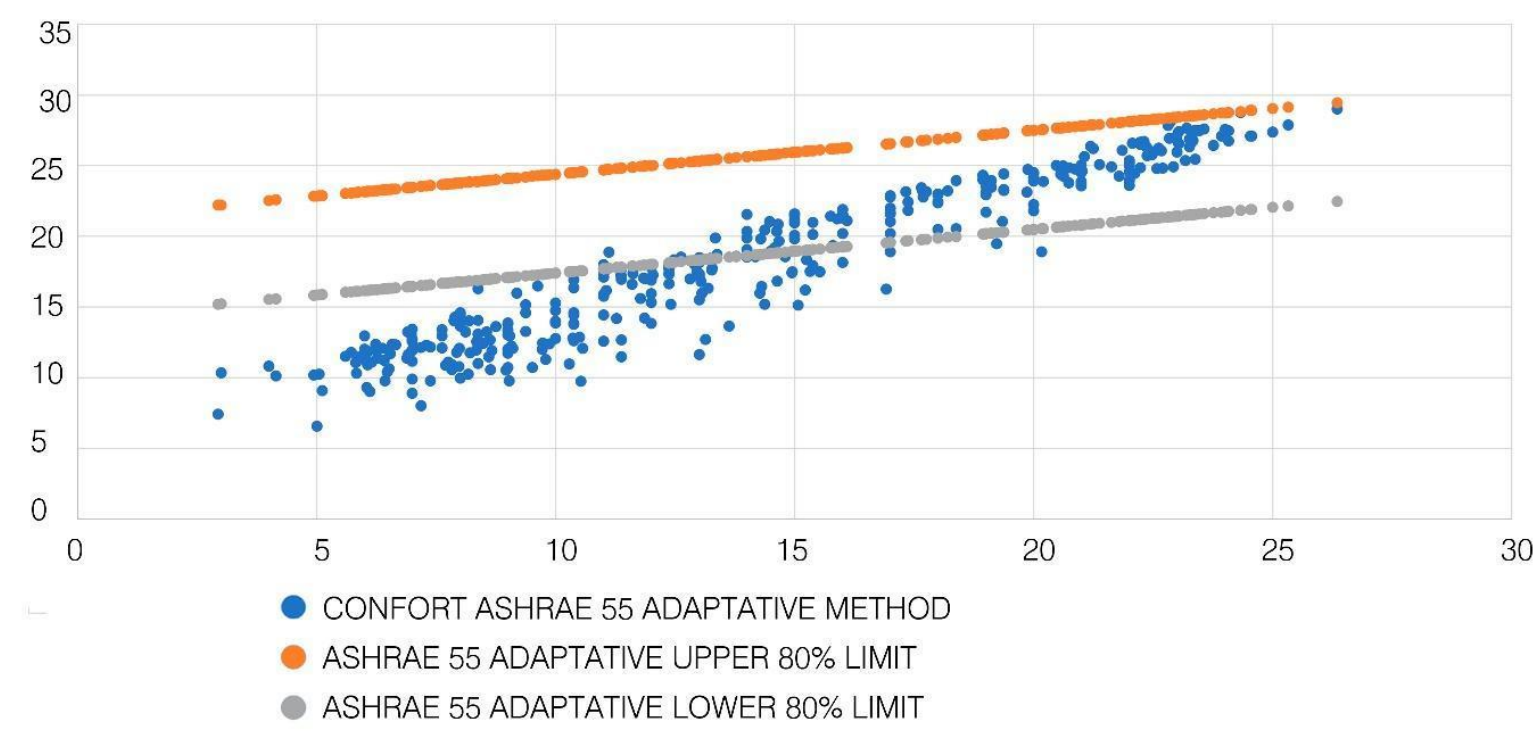

Figure 33. Villa E.1027 evaluation of thermal comfort through the ASHRAE 55 Adaptive Method. $X$ axis: outdoor temperature $\left({ }^{\circ} \mathrm{C}\right) ; Y$ axis: indoor temperature $\left({ }^{\circ} \mathrm{C}\right)$

These results are a clear demonstration of the impact that passive design solutions had in the original design. Therefore, using simulation tools, it can be predicted that the design of villa E.1027 provides adequate thermal conditions so that the occupants could feel comfortable during most of the summer, and even in significantly extended periods (from March to November), if natural ventilation and solar exposure are conveniently and dynamically controlled. Nevertheless, it is clear that the house may need heating in the cold season, as the inhabitants, with a level of clothing and activity according to the use of the house, may feel fresh or even cold. Although the house was a vacation house to enjoy the French Riviera -intended fundamentally for the warm season- the house was also planned for use during the cold season. Accordingly, it was equipped with a heating system and radiators strategically placed near or below the windows, thus helping to compensate for the coldsurface radiation loss through the generous glazing. Additionally, the multipurpose living-room featured an innovative fireplace that was placed on the south facade facing the sea, placed next to the large floor to ceiling window opening that runs along the façade (Gray, Badovici, 1929b, p. 30).

\section{Discussion of results}

Gray and Badovici's text -in their description of the house- on these issues, is very telling. The main goal was to achieve a comfortable design for the 'enjoyment of living'; every detail, form or part of it was conceived to fulfil this purpose without compromising functionality or comfort for the sake of aesthetics or fashion.

Considering the simulation results obtained, Gray's and Badovici's deep understanding of the sun's impact and the cross ventilation needed to provide comfort can be confirmed. All architectural elements evaluated in this research confirmed their role in the process of providing predicted thermal comfort values just as it was foreseen by Gray's and Badovici's project, and anticipated in their writings. The importance of the awnings, the orientable shutter window systems, the positioning and dimensioning of the openings in the facades to enhance cross-ventilation to provide predicted thermal comfort values has also been shown.

The use of thermal comfort evaluation methods to assess comfort in architecture, and the use of simulation software, confirm the designers' intentions. Had they been able to use them, their design, probably, would not have differed much. The results provided by ASHRAE 55 Adaptive method confirm that the house may be within thermal comfort values during the warm part of the year. From this point of view, all three methods share, with slight differences, consistent results. The performed analysis also confirms that some modern architects were concerned with comfort (Requena-Ruiz, 2016) (Iommi, 2019). From the ventilation point of view, Gray's and Badovici's understanding of the location and the influence of the sea breeze together with the design 
solutions confirm other authors' statements on the topic (Cuce et al., 2019).

The evaluation of the house with present day simulation tools has confirmed the importance of the design and its adaptation to its location, and a wise synthesis of vernacular and incipient studies for comfort rationalisation, sharing other authors' opinions (Meir and Roaf, 2003). The importance of sunlight has also been confirmed in the process as well as the need for the specificity of the design features used to control sunlight for each location (Zhang and Birru, 2012) (Zhang and Barrett, 2012). It could also be confirmed that the house has a proper level of illumination depending on the time of the day to allow a flexible use of the space. This must also be understood as an important part in the assessment of architectural space quality (Darula, Christoffersen and Malikova, 2015) (Tzempelikos and Athienitis, 2007).

After performing the simulations throughout the year, the predicted thermal comfort values show that the performance of the house extends beyond the summer period, even offering acceptable comfort values during other periods of the year. In addition, it should be noted that this situation is consistent with the intentions of the designers, since they included enough conditioning systems, heating and fireplace, to allow the use of the house during the cold season or in those days where the climatic conditions might be less favourable.

Finally, this research has some limitations in the available building construction data and in the limitations of the software in terms of the following. Geometrical inconsistencies in the exportation of files among programs, which could have influenced the findings. The introduction of modifying factors for shading systems; and the use of climate databases to make calculations. To investigate the results between simulation and real performance, it would have been necessary to perform onsite measurements and post-occupancy evaluation with all-year-round occupants. This is something that is often not possible in this type of iconic building, as was the case here.

\section{Conclusions}

The use of new technologies and simulation tools can be useful to increase our knowledge and understanding of the overall performance of buildings with architectural value that belong to periods when these tools were not yet available. The methodology used for this research to assess predicted thermal comfort through software simulation tools could well be suggested as a guide to conduct similar research applicable to other modern architectural examples, certainly for new projects.

Despite its unmistakably modern design, the E.1027 house is an outstanding example of architectural performance in terms of comfort optimisation, through the use of passive design solutions. Contrary to common belief, there are, in the E.1027 house and other modern projects, examples of architecture that prove through analysis that despite complying with modern tenets of style and design approach, are indeed fully adapted to their location: as it is proven in this house case-study.

This research also shows the influence of a good passive design in the process of adapting a building to a specific location. Cross-ventilation, solar gains and sun control are key factors that have a critical impact as passive design strategies applied in locations with soft winters, and warm and humid summers. At the same time, this research shows that Gray and Badovici did not only anticipate the house performance and adaptation to its location in their writings, but also managed to achieve a great contemporary architectural design in practice, achieving significant levels of predicted thermal comfort and outstanding design quality.

Further research could be conducted into existing buildings. For example, an extensive analysis of Tempe à Pailla, designed by Eileen Gray, to further explore the influence of the passive architectural designs in relation to site. It may also be illuminating to carry out a comparison between Eileen Gray's designs and other environmental-conscious architects of her time. More widely, it would be possible to conduct in situ measurements of thermal comfort conditions over other architectural examples (culturally significant buildings) to evaluate the deviation of the simulated results over the real building performance. And finally, carry out an extensive research project to evaluate the relation between simulations and post-occupancy evaluations in the process of reaching comfort in buildings.

\section{Acknowledgements}

We would like to publicly acknowledge Professor Carmen Espegel's generosity in allowing us to use her 
redrawn floor plans of villa E.1027 which assisted tremendously to better understand the relation of this architectural project to the site as well as providing us access to sun exposure protection section plans of the main façade. We would also like to thank Professor Tim Benton and Professor Caroline Constant regarding some issues that their knowledge of the house has helped to clarify.

This paper shows some of the results of the research undertaken at UNCC during a sabbatical leave by Professor Carlos L. Marcos, partially funded by the University of Alicante, in collaboration with Dr. Antonio Galiano-Garrigós, Professor Tahar Kouider, and Dr. Pablo J. Juan-Gutiérrez. However, it was triggered from a lecture given at KEA in Copenhagen in April of 2016 by Professor Marcos in an international workshop on Healthy Housing organised by Dr. Antonio Galiano and also attended by Professor Tahar Kouider.

\section{References}

Adam, P. (1989). Eileen Gray and Le Corbusier, 9H, 8, pp. 150-153.

Adam, P. (2000). Eileen Gray, Architect/designer: A Biography (Rev. Ed.). London: Ed. Thames and Hudson.

ASHRAE. Standard 55-Thermal Environmental Conditions for Human Occupancy; American National Standards Institute: New York, NY, USA, 2020.

D'Ambrosio Alfano, FR et al (2013) On the transition thermal discomfort to heat stress as a function of the PMV value. Ind Health. 2013;51(3):285-96.

Banham, R. (1969) La arquitectura del entorno bien climatizado. Buenos Aires: Ed. Infinito. [Banham, R. (1969) Architecture of the Well-Tempered Environment. Chicago:University of Chicago Press]

Benton, T. (2017). 'E-1027 and the Drôle De Guerre'. In: Weaver, Thomas ed. AA Files, Volume 74. Architectural Association, pp. 123-143.

Bluyssen, P. M. (2010) 'Towards new methods and ways to create healthy and comfortable buildings', Building and Environment. Elsevier Ltd, 45(4), pp. 808-818. doi: 10.1016/j.buildenv.2009.08.020.

Brager, G. S. and De Dear, R. J. (1998) 'Thermal adaptation in the built environment: A literature review', Energy and Buildings. Elsevier, 27(1), pp. 83-96. doi: 10.1016/s0378-7788(97)00053-4.

Chenari, B., Dias Carrilho, J. and Gameiro Da Silva, M. (2016) 'Towards sustainable, energy-efficient and healthy ventilation strategies in buildings: A review', Renewable and Sustainable Energy Reviews, 59, pp. 1426-1447. doi: 10.1016/j.rser.2016.01.074.

Cohen, J.L. (2004) Le Corbusier, 1887-1965: The Lyricism of Architecture in the Machine Age. Köln: Taschen.

Colomina, B. (1993). War on Architecture: E.1027. Assemblage, 20, pp. 28-29

Constant, C. (1994). The Nonheroic Modernism of Eileen Gray, Journal of the Society of Architectural Historians, Vol. 53, No. 3 (Sep. 1994), pp. 265-279.

Constant, C. (2000). Eileen Gray. London: Phaidon Press Ltd.

Cuce, E. et al. (2019) 'Sustainable ventilation strategies in buildings: CFD research', Sustainable Energy Technologies and Assessments, 36(May). doi: 10.1016/j.seta.2019.100540.

Diego-Mas, J. A. (2015). Evaluación del confort térmico con el método de Fanger. Ergonautas, Universidad Politécnica de Valencia, 2015, [online]. http://www.ergonautas.upv.es/metodos/fanger/fanger-ayuda.php [Accessed 3-02-2020]. [Evaluation of thermal comfort with the Fanger method. Ergonauts]

Darula, S., Christoffersen, J. and Malikova, M. (2015) 'Sunlight and insolation of building interiors.', Energy Procedia. Elsevier B.V., 78, pp. 1245-1250. doi: 10.1016/j.egypro.2015.11.266.

Escandón, R., Sendra, J. J. and Suárez, R. (2015) 'Energy and climate simulation in the Upper Lawn Pavilion, an experimental laboratory in the architecture of the Smithsons', Building Simulation. Tsinghua University Press, 8(1), pp. 99-109. doi: 10.1007/s12273-014-0197-0.

Espegel, C. (2010). Aires modernos. E.1027: maison en bord de mer Eileen Gray y Jean Badovici 1926-1929. Madrid: Ed. Mairea Libros. [Modern airs. E.1027: maison en bord de mer Eileen Gray and Jean Badovici 1926-1929]

Fabbri, K. (2015) 'Indoor thermal comfort perception: A questionnaire approach focusing on children', Indoor Thermal comfort Perception: A Questionnaire Approach Focusing on Children, pp. 1-302. doi: 10.1007/978-3-319-18651-1.

Fanger, P. O. (1967) 'Calculation of Thermal comfort: Introduction of a Basic Comfort Equation', ASHRAE Transactions, 73(III4.1-III4.20). 
Geva, A. (2008) 'Rediscovering Sustainable Design through preservation: Bauhaus Apartments in Tel Aviv', APT Bulletin: The Journal of Preservation Technology, 39(1), pp. 43-49.

Givoni, B. (1992). Comfort, climate analysis and building design guidelines, Energy and Buildings, 18 (1992), pp. 11-23.

Givoni, B. (1969) Man, climate, and architecture. London: Elsevier Publishing Company Limited.

Granadeiro, V. et al. (2013) 'Building envelope shape design in early stages of the design process: Integrating architectural design systems and energy simulation’, Automation in Construction. doi: 10.1016/j.autcon.2012.12.003.

Gray, E., Badovici,. (1929a). De l'éclecticisme au doute, L’Architecture Vivante, Autumn-Winter 1929, pp. 17-21. [From eclecticism to doubt, L'Architecture Vivante, Autumn-Winter 1929]

Gray, E., Badovici,. (1929b). Description, L’Architecture Vivante, Autumn-Winter 1929, pp. 23-38. [Description, Living Architecture, Autumn-Winter 1929]

Gray, E. and Badovici, J. (1929) E.1027, maison au bord de mer. Paris: Albert Morance. Available at: https://www.worldcat.org/title/E.1027-maison-en-bord-de-mer/oclc/490316665 (Accessed: 1 April 2021). [E.1027, house by the sea. Paris: Albert Morance]

Halawa, E. and Van Hoof, J. (2012) 'The adaptive approach to thermal comfort: A critical overview', Energy and Buildings, pp. 101-110. doi: 10.1016/j.enbuild.2012.04.011.

Hellwig, R. T. et al (2019). A framework for adopting adaptive thermal comfort principles in design and operation of $\begin{array}{lllllll}\text { buildings. } & \text { Energy } & \& & \text { Buildings } & 205 & \text { (2019) } & \text { [online]. }\end{array}$ https://www.sciencedirect.com/science/article/abs/pii/S0378778819316160?via\%3Dihub, [Accessed 10 September 2020].

Hitchcock, H.R. and Johnson, P. (1932) The International Style: Architecture since 1922. New York: W. W. Norton \& Company.

Humphreys, M. A. and Hancock, M. (2007) 'Do people like to feel "neutral" ?'. Exploring the variation of the desired thermal sensation on the ASHRAE scale', Energy and Buildings, 39(7), pp. 867-874. doi: 10.1016/j.enbuild.2007.02.014.

International Standard Organization. Ergonomics of the thermal environment - Analytical determination and interpretation of thermal comfort using calculation of the PMV and PPD indices and local thermal comfort criteria (ISO 7730:2005), 2005.

Iommi, M. (2019) 'Daylighting performances and visual comfort in Le Corbusier's architecture. The daylighting analysis of seven unrealized residential buildings', Energy and Buildings. Elsevier Ltd, 184, pp. 242-263. doi: 10.1016/j.enbuild.2018.12.014.

Kottek, M.; Grieser, J.; Beck, C.; Rudolf, B.; Rubel, F. (2006) World Map of the Köppen-Geiger Climate Classification Updated. Meteorol. Z. 2006, 15, 259-263.

Kumar, S. et al. (2019) 'Comparative study of thermal comfort and adaptive actions for modern and traditional multistorey naturally ventilated hostel buildings during monsoon season in India', Journal of Building Engineering. Elsevier Ltd, 23(January), pp. 90-106. doi: 10.1016/j.jobe.2019.01.020.

Marcos, C. L. (2011). Crítica de género. E.1027: Eileen Gray vs. Le Corbusier en Cap Martin. Feminismo/s, 17, pp. 259296. [Gender criticism. E. 1027: Eileen Gray vs. Le Corbusier in Cap Martin]

Marsh, A. J., (2018). Psychrometric Chart Application. [online]. https://drajmarsh.bitbucket.io/psychro-chart2d.html [Accessed 19 August 2020].

McGuckian, M. (2016). 98 facts about Eileen Gray. Independent; Monday, 2 May 2016.

Meir, I. A. and Roaf, S. C. (2003) 'The future of the vernacular Towards new methodologies', Vernacular architecture in the twenty-first century: Theory, education and practice., (September 2014), pp. 215-230.

Moreno, M.P. (2013). The abstraction of the site. The surrounding's objectification in two houses by Eileen Gray. ZARCH. Journal of interdisciplinary studies in Architecture and Urbanism 1, 320-331.

Ne'Eman, E. (1974) 'Visual aspects of sunlight in buildings', Lighting Research \& Technology. SAGE PublicationsSage UK: London, England, 6(3), pp. 159-164. doi: 10.1177/096032717400600304.

Nicol, J. F. and Humphreys, M. A. (2002) 'Adaptive thermal comfort and sustainable thermal standards for buildings', Energy and Buildings, 34(6), pp. 563-572. doi: 10.1016/S0378-7788(02)00006-3.

Nicol, F. and Roaf, S. (2005) 'Post-occupancy evaluation and field studies of thermal comfort', Building Research and Information, 33(4), pp. 338-346. doi: 10.1080/09613210500161885.

Olesen, B. W. and Parsons, K. C. (2002) 'Introduction to thermal comfort standards and to the proposed new version of 
EN ISO 7730', in Energy and Buildings. Elsevier, pp. 537-548. doi: 10.1016/S0378-7788(02)00004-X.

Olgyay, V. et al. (1963) Design with Climate, Design with Climate. Princeton University Press. doi: 10.2307/j.ctvc77kqb.

Rault, J. (2005) Occupying E.1027. Reconsidering Le Corbusier's «Gift» to Eileen Gray, Space and Culture, Vol. 8, 2, pp. 160-179.

Requena-Ruiz, I. (2011) Arquitectura adaptada al clima en el Movimiento moderno: Le Corbusier (1930-1960), PhD dissertation, Universidad de Alicante. En http://hdl.handle.net/10045/23997 [Climate-adapted architecture in the modern Movement: Le Corbusier (1930-1960)]

Requena-Ruiz, I. (2016) 'Thermal comfort in twentieth-century architectural heritage: Two houses of Le Corbusier and André Wogenscky', Frontiers of Architectural Research. Elsevier, 5(2), pp. 157-170. doi: 10.1016/j.foar.2016.02.001.

Roulet, C. A. et al. (2006) 'Perceived health and comfort in relation to energy use and building characteristics', Building Research and Information, 34(5), pp. 467-474. doi: 10.1080/09613210600822279.

Rykwert, J. (1971). Eileen Gray: two Houses and an Interior, 1926-1933, Perspecta: 13/14, 67-73.

Ryan, D. J. (2010) 'Sunshine and shade in the architecture of Eileen Gray', Architectural Science Review, 53(3), pp. 340347. doi: 10.3763/asre.2010.0028.

Schweiker, M. et al. (2012) 'Development and validation of a methodology to challenge the adaptive comfort model', Building and Environment. Pergamon, 49(1), pp. 336-347. doi: 10.1016/j.buildenv.2011.08.002.

Shi, X. et al. (2016) 'A review on building energy efficient design optimization from the perspective of architects', Renewable and Sustainable Energy Reviews. Elsevier, 65, pp. 872-884. doi: 10.1016/j.rser.2016.07.050.

Summerson, J. (1966) The Classical Language of Architecture. Cambridge MA: The MIT Press.

Torres-Cueco, J. (2004) Le Corbusier: Visiones de la técnica en cinco tiempos. Barcelona: Fundación Caja de Arquitectos. [Le Corbusier: Visions of technique in five times]

Tzempelikos, A. and Athienitis, A. K. (2007) 'The impact of shading design and control on building cooling and lighting demand', Solar Energy, 81(3), pp. 369-382. doi: 10.1016/j.solener.2006.06.015.

Van Hoof, J. (2008). Forty years of Fanger's model of thermal comfort: comfort for all?, Indoor Air; 18: $182-201$.

Yang, L., Yan, H. and Lam, J. C. (2014) 'Thermal comfort and building energy consumption implications - A review', Applied Energy. Elsevier Ltd, 115, pp. 164-173. doi: 10.1016/j.apenergy.2013.10.062.

Zhang, S. and Birru, D. (2012) 'An open-loop venetian blind control to avoid direct sunlight and enhance daylight utilization', Solar Energy. Elsevier Ltd, 86(3), pp. 860-866. doi: 10.1016/j.solener.2011.12.015.

Zhang, Y. and Barrett, P. (2012) 'Factors influencing occupants' blind-control behaviour in a naturally ventilated office building', Building and Environment, 54, pp. 137-147. doi: 10.1016/j.buildenv.2012.02.016. 